\title{
PHARMACEUTICAL EMBODIED TECHNICAL PROGRESS, LONGEVITY, AND QUALITY OF LIFE: \\ DRUGS AS "EQUIPMENT FOR YOUR HEALTH"
}

\author{
Frank R. Lichtenberg \\ Suchin Virabhak \\ Working Paper 9351 \\ http://www.nber.org/papers/w9351
NATIONAL BUREAU OF ECONOMIC RESEARCH
1050 Massachusetts Avenue
Cambridge, MA 02138 \\ November 2002
}

The views expressed herein are those of the authors and not necessarily those of the National Bureau of Economic Research.

(C) 2002 by Frank R. Lichtenberg and Suchin Virabhak. All rights reserved. Short sections of text, not to exceed two paragraphs, may be quoted without explicit permission provided that full credit, including (C) notice, is given to the source. 
Pharmaceutical-embodied technical progress, longevity, and quality of life:

drugs as "equipment for your health"

Frank R. Lichtenberg and Suchin Virabhak

NBER Working Paper No. 9351

November 2002

JEL No. I12, L65, O3

\section{$\underline{\text { ABSTRACT }}$}

Several econometric studies have concluded that technical progress embodied in equipment is a major source of manufacturing productivity growth. Other research has suggested that, over the long run, growth in the U.S. economy's "health output" has been at least as large as the growth in non-health goods and services. One important input in the production of health - pharmaceuticals - is even more R\&D- intensive than equipment.

In this paper we test the pharmaceutical-embodied technical progress hypothesis - the hypothesis that newer drugs increase the length and quality of life — and estimate the rate of progress. To do this, we estimate health production functions, in which the dependent variables are various indicators of post-treatment health status (such as survival, perceived health status, and presence of physical or cognitive limitations), and the regressors include drug vintage (the year in which the FDA first approved a drug's active ingredient(s)) and indicators of pre-treatment health status. We estimate these relationships using extremely disaggregated — prescription- level—cross-sectional data derived primarily from the 1997 Medical Expenditure Panel Survey.

We find that people who used newer drugs had better post-treatment health than people using older drugs for the same condition, controlling for pre-treatment health, age, sex, race, marital status, education, income, and insurance coverage: they were more likely to survive, their perceived health status was higher, and they experienced fewer activity, social, and physical limitations. The estimated cost of the increase in vintage required to keep a person alive is lower than some estimates of the value of remaining alive for one month. One estimate of the cost of preventing an activity limitation is $\$ 1745$, and the annual rate of technical progress with respect to activity limitations is $8.4 \%$. People consuming newer drugs tend to experience greater increases (or smaller declines) in physical ability than people consuming older drugs.

Most of the health measures indicate that the effect of drug vintage on health is higher for people with low initial health than it is for people with high initial health. Therefore in contrast to equipment-embodied technical progress, which tends to increase economic inequality, pharmaceutical-embodied technical progress has a tendency to reduce inequality as well as promote economic growth, broadly defined.

Frank R. Lichtenberg

Columbia University

Graduate School of Business

726 Uris Hall

3022 Broadway

New York, NY 10027

and NBER

frank.lichtenberg@columbia.edu
Suchin Virabhak

Department of Economics

Columbia University

New York, NY 10027

sv102@columbia.edu 
In his seminal 1956 paper, Robert Solow showed that, for sustained economic growth to occur, technological progress is necessary:

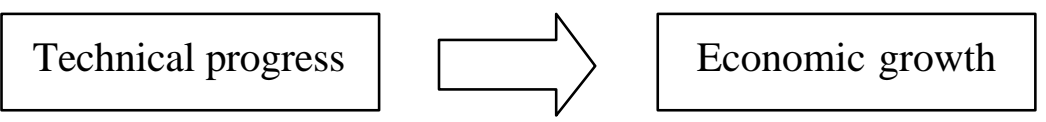

In that paper, Solow assumed that technical progress was exogenous: it descends upon the economy like "manna from heaven," automatically and regardless of whatever else is going on in the economy (Jones (1998, 32-3)).

More recent theoretical ("endogenous growth") models (Romer (1990)) relaxed this assumption: they have hypothesized that "technical progress is driven by research and development" ((Jones $(1998,89-90))$ :

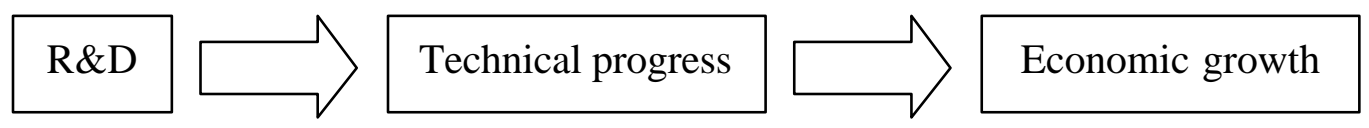

Empirical evidence (e.g. Griliches and Lichtenberg (1984), Lichtenberg and Siegel (199?)) is consistent with the hypothesis that firms and industries that perform more R\&D exhibit higher productivity growth.

Solow and other economists have recognized since the late 1950s that there are two kinds of technical progress: disembodied and embodied.
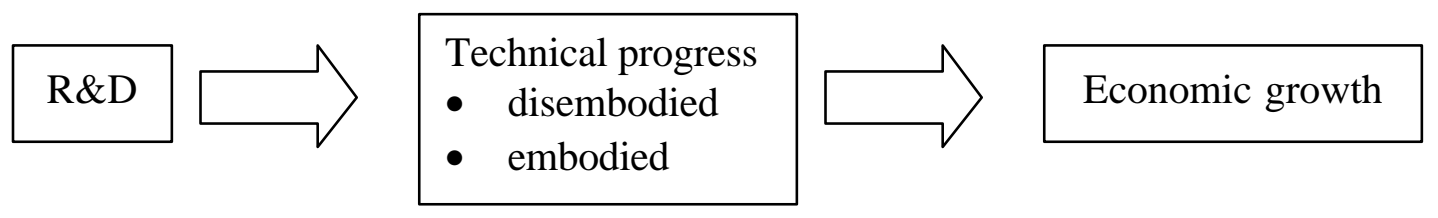

Suppose that agent $\mathrm{i}$ in the economy (e.g. a firm or government agency) engages in research and development. If technical progress is disembodied, another agent (j) can benefit from agent i's R\&D whether or not he purchases agent i's products. But if technical progress is embodied, agent $\mathrm{j}$ benefits from agent i's $R \& D$ only if he purchases agent i's products. Solow conjectured that most technical progress was embodied. In one paper (Solow (1962, p. 76)), he assumed that "all technological progress needs to be 'embodied' in newly produced capital goods before there can be any effect on output."

A number of econometric studies have investigated the hypothesis that capital equipment employed by U.S. manufacturing firms embodies technological change, i.e. 
that "each successive vintage of investment is more productive than the last." Equipment is expected to embody significant technical progress due to the relatively high R\&Dintensity of equipment manufacturers. According to the National Science Foundation, the R\&D-intensity of machinery and equipment manufacturing is about $50 \%$ higher than the R\&D-intensity of manufacturing in general, and $78 \%$ higher than the R\&D intensity of all industries.

One method that has been used to test the equipment-embodied technical change hypothesis is to estimate manufacturing production functions, including (mean) vintage of equipment as well as quantities of capital and labor. Bahk and Gort (1993) argued that "we can take due account of the effect of vintage by measuring the average vintage of the stock" (p. 565). Similarly, Sakellaris and Wilson (2000) stated that "a standard production function estimation (in $\log s$ ) provides an estimate of embodied technical change by dividing the coefficient on average age [of equipment] by the coefficient on capital stock" (capital's share in total cost).

These studies have concluded that technical progress embodied in equipment is a major source of manufacturing productivity growth. Hulten (1992) found that as much as 20 percent (and perhaps more) of the BLS total-factor-productivity change (in manufacturing) can be directly associated with embodiment-the higher productivity of new capital than old capital. For equipment used in U.S. manufacturing, best-practice technology may be as much as 23 percent above the average level of technical efficiency. Bahk and Gort (1993) concluded that "Industrywide learning appears to be uniquely related to embodied technical change of physical capital. Once due account is taken of the latter variable, residual industrywide learning [disembodied technical change] disappears as a significant explanatory variable" (p. 579). And Sakellaris and Wilson (2000) estimate that "each vintage is about 12 percent more productive than the previous year's vintage (in the preferred specification)", and that equipment-embodied technical change accounted for about two thirds of U.S. manufacturing productivity growth between 1972 and 1996.

Although equipment-embodied technical progress has contributed to U.S. economic growth, it has probably had an undesirable side effect: increasing economic 
inequality. ${ }^{1}$ Bartel and Lichtenberg (1987) presented evidence that reductions in the mean age of equipment reduce the relative demand for, and wages of, less-educated workers. Support for the "skill-biased technical change" hypothesis has been provided by numerous other studies.

Although virtually all previous empirical studies of embodied technical progress have focused on equipment used in manufacturing, embodied technical progress may also be an important source of economic growth in another sector of the economy: health care. Recent research has suggested that, over the long run, growth in the U.S. economy's "health output" has been at least as large as the growth in non-health goods and services. ${ }^{2}$

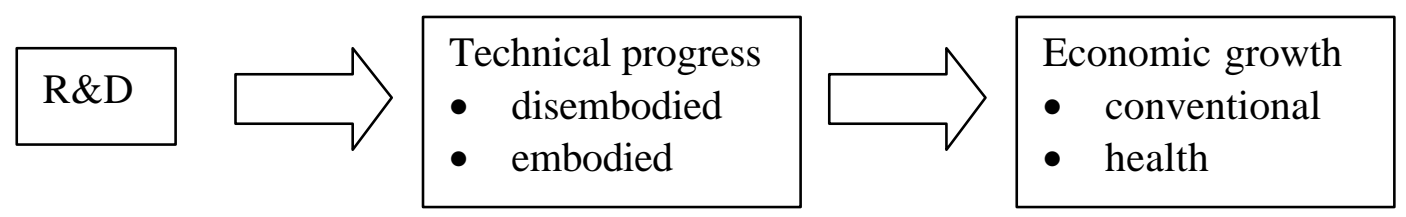

Between 1900 and 1997, life expectancy at birth increased from 49.2 years to 76.5 years Anderson (1999)). Nordhaus (2002) estimated that, "to a first approximation, the economic value of increases in longevity over the twentieth century is about as large as the value of measured growth in non-health goods and services". Moreover, there is evidence that the quality as well as the length of life of life have increased. According to a new study, which looked at a sample of 19,000 Americans age 65 and older, the chances that elderly Americans will be devastated by chronic disabilities like stroke and dementia have declined sharply. The number of older people who become severely disabled has been declining gradually for more than a decade, but the decline became much sharper at the end of the 1990's. ${ }^{3}$

\footnotetext{
${ }^{1}$ According to a recent article, "For 30 years the gap between the richest Americans and everyone else has been growing so much that the level of inequality is higher than in any other industrialized nation....many economists [have] come to see inequality as a basic feature of the new high-tech economic scene." ("Grounded by an income gap," New York Times, Dec. 15, 2001.)

2 Evidently, officials at the United Nations feel that per capita GDP growth is an incomplete measure of economic growth, broadly defined: they publish the "human development index," which is an (unweighted) average of three indexes: a life expectancy index, an education index, and an index of per capita GDP.

${ }^{3}$ Scientists at the National Institute on Aging, which sponsored the study, said the decline probably resulted from a variety of factors, including more widespread knowledge of the benefits of diet and exercise, fewer people smoking, new drugs for heart problems and other illnesses, and advances in eye surgery. Advances in prescription drugs and medical technology have also contributed to the decline. "Decrease in Chronic Illness Bodes Well for Medicare Costs," New York Times, May 8, 2001
} 
Thus health output appears to be increasing at least as fast as conventional output. Moreover, one important input in the production of health—pharmaceuticals — is even more R\&D-intensive than equipment. According to the NSF, the R\&D intensity of drugs and medicines manufacturing is $74 \%$ higher than the R\&D intensity of machinery and equipment manufacturing (Figure 1). Therefore, it is quite plausible that there is also a high rate of pharmaceuticalembodied technical progress.

The objective of this paper is to test the pharmaceuticalembodied technical progress hypothesis- the hypothesis that newer drugs increase the length and quality of life - and to estimate the rate of progress. In one respect, the approach we take is similar to that used in previous studies of manufacturing: we estimate production functions that include vintage. But our methodology differs in a number of ways. We estimate health production functions, in which the dependent variables are various indicators of health status, such as presence of physical or cognitive limitations. We estimate these relationships using extremely disaggregated-prescription-level—cross-sectional data derived primarily from the 1997 Medical Expenditure Panel Survey. And we define vintage as the year in which the Food and Drug Administration (FDA) first approved a drug's active ingredient(s).

\section{Theoretical Framework}

The simplest model one might estimate to determine the effect of drug vintage on post-treatment health is

$$
\mathrm{H}_{\mathrm{POST}}=\mathrm{b}_{0}+\mathrm{b}_{1} \mathrm{~V}+\mathrm{b}_{2} \mathrm{Z}+\mathrm{u}
$$

where:

$\mathrm{H}_{\mathrm{POST}}$ is a measure of a person's post-treatment health status

$\mathrm{V}$ is the vintage (FDA approval year) of the $\operatorname{drug}(\mathrm{s})$ consumed by the person during a period

$\mathrm{Z}$ are other potential determinants of $\mathrm{H}_{\mathrm{POST}}$ that may be correlated with V (e.g. medical condition, age, sex, and education)

$\mathrm{u}$ is a disturbance 
For several reasons, however, the consistency and efficiency of estimates of this effect may be improved by extending eq. (1) to include pre-treatment health status:

$$
\mathrm{H}_{\mathrm{POST}}=\mathrm{b}_{0}+\mathrm{b}_{1} \mathrm{~V}+\mathrm{b}_{2} \mathrm{Z}+\mathrm{b}_{3} \mathrm{H}_{\mathrm{PRE}}+\mathrm{u}
$$

where:

$\mathrm{H}_{\text {PRE }}$ is a measure of a person's pre-treatment health status, i.e. her status at the beginning of the period

We will estimate both models. Estimation of eq. (2) will reveal the effect of vintage on post-treatment health status, conditional on pre-treatment health status. ${ }^{4}$ The first reason to control for $\mathrm{H}_{\mathrm{PRE}}$ is that many of the health indicators that we will analyze are fairly subjective: they are responses to questions such as "do you have difficulty walking?," or "do you suffer from cognitive limitations?". There may be significant differences in the way people whose "true" health is the same respond to such questions. But as long as these differences remain the same in the pre- and post-treatment health surveys, they won't affect our estimates.

The second reason is that HPOST may depend on the vintage of drugs consumed in previous periods as well as the period of observation. Suppose that $H_{P O S T}=f\left(V, V_{-1}, V_{-}\right.$ $2, \ldots)$. If the coefficients on $\mathrm{V}$ decay geometrically with respect to time, one may express $\mathrm{H}_{\mathrm{POST}}$ as a linear function of current $\mathrm{V}$ and its own lagged value $\left(\mathrm{H}_{\mathrm{PRE}}\right)$. Under these assumptions, $\mathrm{b}_{1}$ may be interpreted as the short-run effect of $\mathrm{V}$ on health, and $\left(\mathrm{b}_{1} / \mathrm{C}^{-}\right.$ $\left.\mathrm{b}_{3}\right)$ ) may be interpreted as the long-run effect.

The third reason to control for HPRE is that assignment of drugs to individuals is not random. Moreover, a simple but plausible theory of how drugs are assigned to people, which we sketch below, suggests that V may be (negatively) correlated with

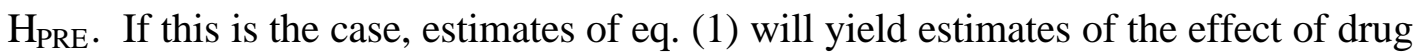
vintage on post-treatment health that are biased downward ${ }^{5}$.

\footnotetext{
${ }^{4}$ If age affects the rate of depreciation of health as well as the level of health (e.g., health declines more rapidly among the elderly), then age should reduce $\mathrm{H}_{\mathrm{POST}}$, conditional on $\mathrm{H}_{\mathrm{PRE}}$.

${ }^{5}$ Another concern is the issue of access to drugs. Should this be restricted, we would expect people with access to newer drugs to have better outcomes, hence rendering the estimates from our proposed model to be potentially misleading. Although it remains unobserved, studies have shown wide variation in health care usage exists among apparently comparable populations living in neighboring communities. For details on small area analysis, refer for instance to Wennberg, John E. et al (1980).
} 
Suppose that a person's (post-treatment) utility function is:

$$
\mathrm{U}=\mathrm{U}\left(\mathrm{H}_{\mathrm{POST}}, \mathrm{Y}-\mathrm{p}_{\mathrm{V}} \mathrm{V}\right)
$$

where:

$\mathrm{Y}$ is the person's gross income (assumed to be exogenous)

$p_{\mathrm{V}}\left(\mathrm{p}_{\mathrm{V}}>0\right)$ is the "price of vintage", i.e. the difference in price between a drug of vintage $t+1$ and a drug of vintage t. ${ }^{6}$ Hence $\left(Y-p_{V} V\right)$ is the person's "residual income", i.e. income net of expenditure on drug vintage.

Further suppose that the (post-treatment) health production function is of the form

$$
\mathrm{H}_{\mathrm{POST}}=\mathrm{H}_{\mathrm{POST}}\left(\mathrm{V}, \mathrm{H}_{\mathrm{PRE}}\right)
$$

where:

$\mathrm{H}_{\mathrm{PRE}}$ is a measure of a person's pre-treatment health status (also assumed to be exogenous).

Assume that the partial derivatives of $\mathrm{H}_{\mathrm{POST}}$ with respect to both $\mathrm{V}$ and $\mathrm{H}_{\mathrm{PRE}}$ are positive: increases in pre-treatment health and in drug vintage both increase post-treatment health.

Eq. (1) can be regarded as a linear version of eq. (4), in which HPRE is included in the disturbance.

Substituting (4) into (3),

$$
\mathrm{U}=\mathrm{U}\left(\mathrm{H}_{\mathrm{POST}}\left(\mathrm{V}, \mathrm{H}_{\mathrm{PRE}}\right), \mathrm{Y}-\mathrm{p}_{\mathrm{V}} \mathrm{V}\right)
$$

Using newer drugs (increasing V) affects utility in two opposite ways: it increases U by increasing $\mathrm{H}_{\mathrm{POST}}$, but reduces utility by reducing residual income $\left(\mathrm{Y}-\mathrm{p}_{\mathrm{V}} \mathrm{V}\right)$. A utilitymaximizing consumer chooses $\mathrm{V}$ to balance these two effects.

We now make one further assumption about the health production function (4): a “negative interaction" between $\mathrm{V}$ and $\mathrm{H}_{\mathrm{PRE}}\left(\left(\partial^{2} \mathrm{H}_{\mathrm{POST}} / \partial \mathrm{V} \partial \mathrm{H}_{\mathrm{PRE}}\right)<0\right)$, i.e. we assume that the marginal productivity of increasing $\mathrm{V}$ is higher for people with poor initial health (low $\mathrm{H}_{\mathrm{PRE}}$ ). (Figure 2) As a rule, increases in the quantity and quality of medical care are probably more valuable to people in poor initial health than they are to people in

\footnotetext{
${ }^{6}$ We will present evidence about $\mathrm{p}_{\mathrm{V}}$ below.
} 
excellent initial health. We will present empirical evidence that provides strong support for this negative interaction.

Since people with low education and income are more likely to be in poor initial health than people with high education and income, pharmaceutical-embodied technical progress may be biased towards the less-educated. ${ }^{7}$ If so, it tends to reduce inequality as it contributes to economic growth. ${ }^{8}$

These assumptions imply that (for given Y), equilibrium V is inversely related to $\mathrm{H}_{\mathrm{PRE}}$ : individuals in poor initial health will tend to use newer drugs than people in excellent initial health. This is why $b_{1}$ from equation (1) may underestimate the effect of $\mathrm{V}$ on $\mathrm{H}_{\text {POST }}$. Suppose that the true post-treatment health production function is a linear version of eq. (4):

$$
\mathrm{H}_{\mathrm{POST}}=\beta_{0}+\beta_{1} \mathrm{~V}+\beta_{2} \mathrm{Z}+\beta_{3} \mathrm{H}_{\mathrm{PRE}}+\mathrm{u}
$$

Then $\operatorname{plim}\left(b_{1}\right)=\beta_{1}+\beta_{3} \beta_{\text {PRE.V }}$, where $\beta_{\text {PRE.V }}$ is the slope coefficient from the simple “auxiliary" regression of $\mathrm{H}_{\mathrm{PRE}}$ on V. Since we hypothesize that $\beta_{3}>0$ and $\beta_{\text {PRE.V }}<0$, $\operatorname{plim}\left(b_{1}\right)<\beta_{1}$.

Fortunately, we have data on $\mathrm{H}_{\mathrm{PRE}}$ as well as on HPOST and V, so we can estimate eq. (5), i.e. we can control for pre-treatment health. In fact, we can extend and generalize the model as follows:

$$
\mathrm{H}_{\mathrm{POST}}=\beta_{0}+\beta_{1} \mathrm{~V}+\beta_{2} \mathrm{Z}+\beta_{3} \mathrm{H}_{\mathrm{PRE}}+\beta_{4}\left(\mathrm{~V} * \mathrm{H}_{\mathrm{PRE}}\right)+\mathrm{u}
$$

According to the "negative interaction" hypothesis discussed above, inclusion of the interaction term $\left(\mathrm{V} * \mathrm{H}_{\mathrm{PRE}}\right)$ is appropriate.

We have argued that controlling for initial health status affords a better representation of the health production function than one without. However, the health

\footnotetext{
${ }^{7}$ Provided that the less-educated have access to new drugs. Lleras-Muney and Lichtenberg (2002) find that less-educated people use older drugs than more-educated people, but the difference in mean age of drugs is very small. The Medicaid program has been the main source of access to new (and old) drugs by lesseducated people for the last 30 years.

${ }^{8}$ Inequality in household income increased during the period 1970-95: the share of U.S. aggregate income received by the top $20 \%$ of households increased from $43.3 \%$ in 1970 to $48.7 \%$ in 1995; the share received by the top $5 \%$ increased from $16.6 \%$ to $21.0 \%$. In contrast, inequality in longevity declined: the coefficient of variation of mean age at death declined by about 7\%, from 26.6 to 24.7. (Infant deaths are excluded from these calculations.) In general, the outward shift of the age-at-death distribution was larger at the left (at young ages) than it was at the right.
} 
production function in equation (7) still fails to account for health shocks that may occur during the interim between the initial health and post-treatment health 'snapshots'. Although health shock events are unobservable, we have reason to believe that including treatment responses could help capture their impact. In other words, by incorporating health utilization measures such as the quantity of prescription drugs, physician visits, and inpatient discharges into our regression, we could, to some extent, account for adverse health shocks ${ }^{9}$. With this interpretation, we would expect a negative relationship between health utilization and post treatment health status - a person who encounters adverse health shocks would receive more treatment. Under this specification, the health production function in equation (4) takes the form:

$$
\mathrm{H}_{\mathrm{POST}}=\mathrm{H}_{\mathrm{POST}}\left(\mathrm{V}, \mathrm{H}_{\mathrm{PRE}}\right. \text {, Health Shocks) }
$$

Further, using health utilization as a proxy for shocks and assuming a linear production function, we modify equation (6) to give:

$$
\begin{aligned}
\mathrm{H}_{\mathrm{POST}}= & \beta_{0}+\beta_{1} \mathrm{~V}+\beta_{2} \mathrm{Z}+\beta_{3} \mathrm{H}_{\mathrm{PRE}} \\
& +\beta_{4} \text { Prescription }+\beta_{5} \text { Physician }+\beta_{6} \text { Hospital }+\mathrm{u}
\end{aligned}
$$

where:

Prescription refers to the number of prescriptions

Physician is the number of physician visits

Hospital is the number of inpatient admissions

$\beta_{4}, \beta_{5}$, and $\beta_{6}$ are postulated to be negative

The model specified in equation (8) poses an additional estimation concern for the drug vintage coefficient. If the quality of drugs affects health status, then it must certainly affect the extent to which a person utilizes other health treatments. This implies that (for any given post-treatment health status), equilibrium $\mathrm{V}$ is inversely related to each health utilization variable: individuals who use newer drugs would also tend to need

\footnotetext{
${ }^{9}$ Notice that our proposed health utilization variables represent quantitative rather than qualitative health 'consumption' (unlike our drug vintage coefficient), which should therefore effectively measure the degree of adverse health events.
} 
quantitatively less treatment in the form of drugs, physician visits and/or inpatient care ${ }^{10}$. For ease of exposition, let's assume a composite variable denoting health utilization, UTIL, with respective slope coefficient, $\beta_{\text {UTIL }}$. If V and UTIL are negatively related, we expect $b_{1}$ from equation (1) may 'overestimate' the effect of $\mathrm{V}$ on $\mathrm{H}_{\mathrm{POST}}{ }^{11}: \operatorname{plim}\left(\mathrm{b}_{1}\right)=\beta_{1}$ $+\beta_{\text {UTIL }} \beta_{\text {UTIL.V, where }} \beta_{\text {UTIL.V }}$ is the slope coefficient from the "auxiliary" regression of UTIL on V. The first term, $\beta_{1}$ can be interpreted as the direct effect of V on HPOsT, while

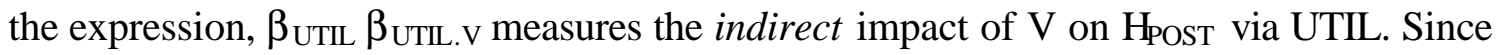
we hypothesize that $\beta_{\mathrm{UTIL}}<0$ and $\beta_{\mathrm{UTIL} . \mathrm{V}}<0, \operatorname{plim}\left(\mathrm{b}_{1}\right)>\beta_{1}$. In short, a priori, we anticipate a lower drug vintage coefficient when we include health utilization. However, this does not necessarily imply that the overall impact of $\mathrm{V}$ on $\mathrm{H}_{\mathrm{POST}}$ is overestimated when utilization is excluded. Adjusting for utilization simply decomposes drug vintage into its direct and indirect effects.

\section{Data}

In order to estimate eq. (6), and determine the effect of drug vintage on posttreatment health, conditional on pre-treatment health and a large number of covariates, we will use data from the household component of the 1997 Medical Expenditure Panel Survey (MEPS). The household component collected data on a sample of families and individuals, drawn from a nationally representative subsample of households, which permits generalization to the entire civilian noninstitutionalized population of the United States. The objective was to produce annual estimates for a variety of measures of health status, health insurance coverage, health care use and expenditures, and sources of payment for health services. The panel design of the survey, which features several rounds of interviewing, makes it possible to determine how changes in respondents' health status, income, employment, eligibility for public and private insurance coverage, use of services, and payment for care are related.

The 1997 MEPS household component collected data on 34,551 people. Each person was interviewed a number of times, and data on the person's use of medical

\footnotetext{
${ }^{10}$ There is empirical support for this claim. Using 1996 Medical Expenditure Panel Survey, Lichtenberg (2001) finds evidence that the replacement of older by newer drugs results in reductions in mortality, morbidity, and total medical expenditure.

${ }^{11}$ For simplicity, we ignore the interaction between $\mathrm{V}$ and $\mathrm{H}_{\text {pre }}$ that was previously discussed.
} 
services throughout the year (including data on each of their 234,532 prescribed medicines) were collected. ${ }^{12}$

To measure pre-treatment health status $\left(\mathrm{H}_{\mathrm{PRE}}\right)$ and covariates $(\mathrm{Z})$, we use data collected at the end of round 3 for Panel 1 and round 1 for Panel 2. To measure posttreatment health status $\left(\mathrm{H}_{\mathrm{POST}}\right)$, we use data collected at the end of round 5 for Panel 1 and round 3 for Panel 2. To measure drug vintage V (and other drug attributes, i.e. medical condition and price), we use data on all of the prescribed medicine events that occurred during rounds 4 and 5 for Panel 1 and rounds 2 and 3 for Panel 2. The time-line of health interviews and prescribed medicine events is depicted in Figure 3.

Health status measures. Responses to the following questions about health status were obtained at both interviews:

- Perceived health status (excellent, very good, good, fair, poor)

- Any limitation work/housework/school? (yes, no)

- Any social limitations? (yes, no)

- Any cognitive limitations? (yes, no)

- Any limitation in physical functioning? (yes, no)

- Difficulty lifting 10 pounds? (no difficulty, some difficulty, a lot of difficulty, unable to do)

- Difficulty walking up 10 steps? (no difficulty, some difficulty, a lot of difficulty, unable to do, completely unable to walk)

- Difficulty walking 3 blocks? (no difficulty, some difficulty, a lot of difficulty, unable to do)

- Difficulty walking a mile? (no difficulty, some difficulty, a lot of difficulty, unable to do)

- Difficulty standing 20 minutes? (no difficulty, some difficulty, a lot of difficulty, unable to do)

- Difficulty bending/stooping? (no difficulty, some difficulty, a lot of difficulty, unable to do)

- Difficulty reaching overhead? (no difficulty, some difficulty, a lot of difficulty, unable to do)

- Difficulty using fingers to grasp? (no difficulty, some difficulty, a lot of difficulty, unable to do)

\footnotetext{
${ }^{12}$ Average number of rx's per person (including people with zero rx's): 6.8. Average number of rx's per person (excluding people with zero rx's): 11.4. $41 \%$ of people had zero rx's.
} 
We recoded all of our health measures to take the value 0 for the worst health outcome ("zero health output") and the value 1 for the best health outcome ("maximum health output"). Using the perceived health status measure and a mortality indicator (whether the person was alive at the time of the second interview), we constructed a composite quality-of-life indicator: ( $1=$ excellent health, $0.8=$ very good health, $0.6=$ good health, $0.4=$ fair health, $0.2=$ poor health, $0=$ dead). For the difficulty measures, we compute the average across all eight indicators and name the composite, 'mean level of difficulty' ${ }^{13,14}$.

Drug information. For each prescription obtained between the two interviews, we extracted the following information from the 1997 MEPS Prescribed Medicine Events file (HC-016A): the National Drug Code (NDC), the 3-digit ICD9 diagnosis for which the drug was prescribed, and expenditure (by all payers) for the prescription. We used the "denorm" table in Multum's Lexicon to identify the active ingredients contained in each NDC product. In September 2000 there were 1830 active ingredients listed in Multum's Lexicon. The FDA approved 92 new molecular entities during 1998-2000, so there would have been about 1738 active ingredients in 1997 . However only 789 of these ingredients were contained in products represented in the 1997 MEPS Prescribed Medicine Events file. To determine the vintages (FDA approval dates) of these ingredients, we used two unpublished files obtained from the FDA. The first is a list of all of the 821 new molecular entities (NMEs) approved during the period 1950-1993. The second is a list of all new drug applications (NDAs) approved during the period 1939-1998. (The first FDA drug approval occurred in 1939.) This list includes both new molecular entities approved and other NDAs approved (new formulations, new manufacturers, etc.). Although the two lists are broadly consistent, there are some discrepancies. Figure 4 shows the number of new molecular entities approved per year,

\footnotetext{
${ }^{13}$ The other health status variables available from the MEPS dataset do not permit us to compute 'reasonable' (composite) continuous health status. We employ this strategy exclusively for our 'mean level of difficulty' measure. See Wells (1996) for a discussion of the construction of health status variables using survey results.

${ }^{14}$ During the interviews, the list of 7questions pertaining to detailed physical activities were asked only to respondents who indicated having limitations in physical functioning. We recoded all respondents with no physical limitation as having 'no difficulty' in the set of all detailed physical activities.
} 
as computed from both lists. ${ }^{15}$ We consider the first list to be more reliable for the 19501993 period, since the FDA constructed it for the specific purpose of identifying NMEs approved during the period. We use the second list only to provide data on NMEs approved during 1939-1949 and 1994-1997. We matched Multum active ingredient names to ingredient names contained in FDA new molecular entity approvals.

Only 60 percent (470 / 789) of the ingredients reported in the 1997 MEPS data appeared in the list of NMEs approved during 1939-1997. Ingredients with known FDA approval dates accounted for 69 percent $\left(167,667\right.$ / 241,314) of MEPS prescriptions. ${ }^{16}$ Table 1 lists the top 20 active ingredients, ranked by number of prescriptions, in the 1997 MEPS. The top 20 ingredients (2.5 percent of MEPS ingredients) accounted for almost 30 percent of all MEPS prescriptions. Four of the top ten, and five of the top twenty, ingredients did not appear in the list of NMEs approved during 1939-1997; their vintages are unknown but presumably precede 1939. The average cost of a prescription of unknown vintage is $\$ 21.88$, and the average cost of a prescription of known (1939-1997) vintage is $\$ 41.10$. Forty-nine percent of prescriptions for drugs of unknown vintage are generic, compared to 36 percent of prescriptions for drugs of known vintage.

There are several ways of handling the problem of censoring of the vintage distribution of drugs. One way is to simply exclude prescriptions for drugs of unknown vintage. This would not affect the consistency of our estimates, provided that the rate of pharmaceuticalembodied technical progress was the same after 1939 as it was before 1939. It would, however, reduce the precision (efficiency) of our estimates, for two reasons. First, it would reduce the size of the sample by almost a third. Second, and probably more importantly, it would substantially reduce the range (and variance) of vintage. The greater this range, the greater the precision of the estimate of $\beta_{1}\left(=\delta \mathrm{H}_{\mathrm{POST}} /\right.$ $\delta \mathrm{V}) .^{17}$

\footnotetext{
${ }^{15}$ We also merged the two lists, by new drug approval number, and calculated the difference in approval years recorded in the two lists. The mean and median differences were both approximately zero, and $98 \%$ of the differences were between -2 and +2 years, but there were 5 cases in which the absolute difference exceeded 10 years.

${ }^{16}$ These figures treat a prescription for a combination drug — a drug with multiple ingredients — as a prescription for each ingredient. For example, a prescription for a drug containing the two ingredients benzalkonium chloride and tyloxapol is treated as two prescriptions, one for each ingredient.

${ }^{17}$ If you seek to identify the effect of $\mathrm{X}$ on $\mathrm{Y}$, you want $\mathrm{X}$ to vary a lot.
} 
An alternative approach is to include prescriptions for drugs of unknown vintage in the sample, but replace $\mathrm{V}$ by a dummy variable whose value depends on the ingredient's location in the vintage distribution. Suppose we divide drugs into two groups: "new drugs" (drugs whose vintage is nonmissing and greater than a certain value (e.g., 1970)), and "old drugs" (other drugs, including those of unknown vintage). Let $\mathrm{V}_{\mathrm{N}}$ represent the mean vintage of new drugs and $\mathrm{V}_{\mathrm{o}}$ the mean vintage of old drugs. (We discuss below how the latter may be computed.) Now define a dummy variable equal to $\mathrm{V}_{\mathrm{N}}$ if the drug is a new drug and equal to $\mathrm{V}_{\mathrm{o}}$ if the drug is an old drug. If we replace $\mathrm{V}$ by this dummy variable in eq. (7), its coefficient is an estimate of the "average annual" effect of vintage on health. ${ }^{18}$ This model can also be estimated on the sample excluding prescriptions with missing vintages.

A third approach is to include prescriptions for drugs of unknown vintage in the sample, and impute an average vintage value (e.g., $\mathrm{V}=1900)$ when vintage is unknown. Imputation enables estimation of our original model (eq. (6)), but since the appropriate value to impute is unknown, we should perform sensitivity analysis by trying alternative values. We report estimates based on two different imputed values, 1900 and 1920.

To summarize, we will estimate five different versions of the model:

\begin{tabular}{|l|l|l|}
\hline & $\begin{array}{l}\text { Missing-vintage rx's } \\
\text { excluded }\end{array}$ & Missing-vintage rx's included \\
\hline linear vintage & & $\begin{array}{l}\text { assume missing V }=1900 \\
\text { assume missing V }=1920\end{array}$ \\
\hline vintage dummy & &
\end{tabular}

Covariates. All of the models we estimate include one prescription-level covariate-the diagnosis for which the drug was consumed - and the following person-level covariates:

\footnotetext{
${ }^{18}$ Wald (1940) was apparently the first to propose using this kind of dummy variable as an instrument for a regressor subject to measurement error. Censoring of vintages may not be the only source of vintage measurement error. One reason is that there is probably considerable variation in the lag between the time of drug discovery and the time of FDA approval; the former may be a more appropriate measure of vintage, but is unobserved. A second is that some drugs ("standard review" drugs) may be very similar to previously approved ("priority review") drugs; perhaps the "effective vintage" of standard-review drugs is the vintage of the preceding priority-review drugs to which they are similar.
} 
age, sex, race, education, income, marital status, and indicators of insurance coverage (Medicare, Medicaid, and private insurance). All variables except income are included as classification variables, e.g. there is a separate dummy variable for each diagnosis (over 600 diagnoses) and each year of age and education.

Unit of analysis. The unit of analysis is a prescription ${ }^{19}$, so the model captures the effect of a change in the vintage of a single prescription on the consumer's post-treatment health. (To calculate the health effect of changing the average vintage of all of a person's prescriptions, one would multiply by the number of her prescriptions.) Each observation contains the vintage of the $\operatorname{drug}^{20}$, the diagnosis for which the drug was prescribed, the pre- and post-treatment health status of the person cons uming the drug, and person-level covariates. Hence, the model is of the form:

$$
\begin{aligned}
\mathrm{H}_{\mathrm{POST}, \mathrm{i}}=\beta_{0}+\beta_{1} \mathrm{~V}_{\mathrm{ij}} & +\beta_{2} \mathrm{Z}_{\mathrm{i}}+\beta_{3} \mathrm{H}_{\mathrm{PRE}, \mathrm{i}}+\beta_{4}\left(\mathrm{~V}_{\mathrm{ij}} * \mathrm{H}_{\mathrm{PRE}, \mathrm{i}}\right) \\
& + \text { diagnosis effects }+\mathrm{u}_{\mathrm{ij}}
\end{aligned}
$$

where $\mathrm{V}_{\mathrm{ij}}$ denotes the jth prescription consumed by person $\mathrm{i}$.

Estimation issues. Due to the categorical nature of the $\mathrm{H}_{\mathrm{POST}}$ measures listed above, ideally one would estimate model (7) using an (ordered) probit or similar procedure. Unfortunately, due to the large number of ("nuisance") parameters in the model (600+ diagnosis effects, 100 age effects, 20 education effects, etc.), the probit estimation procedure often failed to converge. Second, our unit of observation is at the prescription level, allowing individuals with more than one prescription event to have multiple entries. We correct for the correlation across such observations by reporting estimates of eq. (7)

\footnotetext{
${ }^{19}$ Hence, if person A had 10 prescriptions and person B had 5, person A would contribute twice as many observations to the sample. Unweighted estimation at the prescription level is similar to weighted estimation at the person level, where the weight is the person's number of prescriptions. Since diagnosis can vary across prescriptions for a given individual, it is easier to control for diagnosis at the prescription level than it is at the person level.

${ }^{20}$ In principle, it would be desirable to decompose approvals not only according to active ingredients, but to different combinations and dosages as well, as these may affect the efficacy of drugs to some degree. However, this is difficult to implement in practice. Moreover, FDA data indicate that new ingredients are more likely to be significant innovations than new formulations or combinations of existing ingredients. Our data reveal that $42 \%$ of the new molecular entities (NMEs) approved during 1990-2001 were "priorityreview approvals" i.e. considered by the FDA to represent "significant improvement compared to marketed products, in the treatment, diagnosis, or prevention of a disease". On the other hand, only $14 \%$ of non-NME NDAs (including new formulations or combinations) approved were priority-review approvals.
} 
using a random effects model that accounts for clustered standard errors ${ }^{21}$. For binary dependent variables, this is known as the "linear probability model," which has certain limitations. We hope to supersede these limitations in the future.

Suppose that HPOST,i equals 1 if person $\mathrm{i}$ has no limitation in physical functioning post-treatment, and otherwise equals zero. Within the linear probability model framework, $\beta_{1}$ is the (short-run) effect of a one-year increase in vintage on the probability of no limitation in physical functioning. ${ }^{22}$ An estimate of $\beta_{1}$ allows us to calculate both (1) the increase in drug cost necessary to achieve a given improvement in post-treatment health, and (2) the rate of pharmaceuticalembodied technical progress.

Let $\mathrm{P}_{\mathrm{rx}}$ represent the price of a prescription. Then $\mathrm{dP}_{\mathrm{rx}} / \mathrm{dV}$ is the derivative of prescription price with respect to vintage - the slope of the vintage-price profile. $\beta_{1}=$ $\mathrm{dH}_{\mathrm{POST}} / \mathrm{dV}$ is the derivative of post-treatment health with respect to vintage - the slope of the vintage-health profile. Hence $\left(\mathrm{dP}_{\mathrm{rx}} / \mathrm{dV}\right) / \beta_{1}=\mathrm{dP}_{\mathrm{rx}} / \mathrm{dH}_{\mathrm{POST}}$ is the cost of the increase in vintage necessary to achieve a given improvement in post-treatment health. For example, if $\mathrm{dP}_{\mathrm{rx}} / \mathrm{dV}=\$ 1.50$ (prescription cost increases at the rate of $\$ 1.50$ per year of vintage) and $\beta_{1}=.00018$, then $\mathrm{dP}_{\mathrm{rx}} / \mathrm{dH}_{\mathrm{POST}}=\$ 1.50 / .00018=\$ 8433$. The increase in vintage required to achieve a .01 increase in the probability of no limitation in physical functioning would increase prescription cost by $\$ 84.33 .^{23}$

The percentage change in the probability of no limitation from a one-year increase in vintage is $\beta_{1} /$ mean $\left(\mathrm{H}_{\mathrm{POST}}\right)$. For example, if $\beta_{1}=.00018$ and mean $\left(\mathrm{H}_{\mathrm{POST}}\right)=$ .671 , the percentage change in probability from a one-year increase in vintage is .00018 /

\footnotetext{
${ }^{21}$ In addition, we attempted the alternative of weighting each observation by the inverse of the number of prescriptions received by that individual - the estimates generally showed a lower standard error, and remained significant.

${ }^{22}$ Assuming for simplicity that there is no interaction effect (i.e. that $\beta_{4}=0$ ). The long-run effect is $-\beta_{1}$ / $\left(1-\beta_{3}\right)$.

${ }^{23}$ This approach can also be used to estimate the cost of the increase in vintage necessary to achieve a oneyear increase in life exp ectancy. Suppose that $\mathrm{H}_{\mathrm{POST}}$ is equal to 1 if the person was alive at the date of the second interview, and equal to zero if the person had died. Then $\beta_{1}$ is the effect of vintage on the probability of survival. Let $L E(t)$ represent a person's remaining life expectancy at year $t$, and $S(t, t+1)$ represent the probability of survival from age $t$ to age $t+1$. Then $\operatorname{LE}(t) \approx S(t, t+1) *[1+L E(t+1)]$, and $\mathrm{dLE} / \mathrm{dV} \approx[1+\mathrm{LE}(\mathrm{t}+1)] *(\mathrm{dS} / \mathrm{dV})=[1+\mathrm{LE}(\mathrm{t}+1)] * \beta_{1}$. Hence, we can obtain an approximate estimate of the effect of a one-year increase in vintage on life expectancy by multiplying $\beta_{1}$ by mean remaining life expectancy of drug consumers. Since their mean age is 53, their mean remaining life expectancy is about 25 years. The cost of the increase in vintage necessary to achieve a one-year increase in life expectancy is therefore $\left(\mathrm{dP}_{\mathrm{rx}} / \mathrm{dV}\right) /\left(25 * \beta_{1}\right)$.
} 
.671 , or .00027 . Previous authors have argued that the annual rate of embodied technical progress should be measured as the percentage change in output from a one-year increase in the vintage of an input divided by the input's share in total cost of production. In our model, each prescription is regarded as a distinct input. The mean (across prescriptions) ratio of the cost of the prescription to total medical expenditure is $0.54 \%$. ${ }^{24}$ Hence in this example (using this indicator of health), the rate of pharmaceuticalembodied technical progress is $.00027 / .0054=5.0 \%$ per year. $^{25}$

Estimates like these, while computed from cross-sectional micro data, have aggregate time-series implications. Mean vintage of drugs consumed tends to increase over time, e.g. drugs consumed in 1997 are of later vintage than drugs consumed in 1977. (In a steady state, the mean vintage of drugs would increase at the rate of one year per year.) The National Institute of Aging-sponsored study cited above found that "the number of older people who become severely disabled has been declining gradually for more than a decade, but the decline became much sharper at the end of the 1990's." 26 As Figure 4 indicates, there was a large increase in the mid-1990s in the number of new drugs approved. This increase, which was primarily due to enactment of the Prescription Drug User Fee Act, may help to explain the acceleration in the decline in disability at the end of the 1990s.

Descriptive statistics. Summary statistics are presented in Table 2. These are presented at both the person level and the prescription level. The prescription-level statistics can be thought of as weighted person-level statistics, where the weight is the person's number of prescriptions. People in poor health tend to consume more prescriptions than people in

\footnotetext{
${ }^{24}$ This ignores the value of the time people devote to their own health care. As Folland et al (2001, p. 121) note, "The consumer does not merely purchase health passively from the market. Instead, the consumer produces it, spending time on health-improving efforts in addition to purchasing medical inputs." Accounting for the value of time would reduce the ratio of the cost of the prescription to total health care cost, and increase the estimated rate of pharmaceutical-embodied technical progress.

${ }^{25}$ The estimated rate of pharmaceutical-embodied technical progress is invariant with respect to the scale, but not the location, of the $\mathrm{H}_{\mathrm{POST}}$ measure. Suppose that $\mathrm{Y}^{*}=\mathrm{c}_{1} \mathrm{Y}$, where $\mathrm{c}_{1}$ is a scale parameter (constant). Then if $b$ is the slope of the regression of $Y$ on $X$, and $b^{*}$ is the slope of the regression of $Y^{*}$ on $X$, $b^{*} /$ mean $\left(Y^{*}\right)=\left(c_{1} b\right) /\left(c_{1}\right.$ mean $\left.(Y)\right)=b /$ mean $(Y)$. But if instead $\mathrm{Y}^{*}=c_{0}+c_{1} Y$, where $c_{0}$ is a location parameter (constant), $b^{*} /$ mean $\left(\mathrm{Y}^{*}\right)=\left(\mathrm{c}_{1} \mathrm{~b}\right) /\left(\mathrm{c}_{0}+\mathrm{c}_{1} \operatorname{mean}(\mathrm{Y})\right) \neq \mathrm{b} / \operatorname{mean}(\mathrm{Y})$. We code all of our HPost measures to take the value 0 for the worst health outcome ("zero health output") and the value 1 for the best health outcome ("maximum health output").

26 "Decrease in Chronic Illness Bodes Well for Medicare Costs," New York Times, May 8, 2001.
} 
excellent health, so prescription-level mean health is lower than person-level mean health. For example, $8 \%$ of individuals reported limitations in physical functioning in the initial interview, but $32 \%$ of prescriptions were consumed by individuals who reported limitations in physical functioning in the initial interview. Similarly, $0.26 \%$ of the individuals had died by the date of the second interview, but $0.80 \%$ of prescriptions were consumed by individuals who had died by the date of the second interview. ${ }^{27}$

\section{Results}

Table 3 presents estimates of $\beta_{1}$ from equation $\mathrm{H}_{\mathrm{POST}, \mathrm{i}}=\beta_{0}+\beta_{1} \mathrm{~V}_{\mathrm{ij}}+\beta_{2} \mathrm{Z}_{\mathrm{i}}+$ diagnosis effects $+u_{i j}$ (excluding pre-treatment health), based on alternative samples (excluding vs. including observations with unknown vintages) and alternative measures of vintage (continuous vs. discrete). It also presents (in the first row) estimates of the effect of vintage on the price of a prescription in 1997.

The first column reports estimates based on the subset of observations where vintage is known, and where the vintage measure is continuous. The Rx price coefficient of 1.25 indicates that a one-year increase in vintage increases the price of a prescription by $\$ 1.25(3.2 \%)$, on average. Looking down the first column, only one of the vintage coefficients_-on "absence of social limitations"--is significant at the 5 percent level.

Estimates reported in the second column are also based on the subset of observations where vintage is known, but the vintage measure is discrete: if the vintage is less than or equal to 1970, it is replaced by the mean vintage of 1939-1970 drugs (1957.7), and if the vintage is greater than 1970, it is replaced by the mean vintage of 1971-1997 drugs (1984.6). A number of the coefficients on this discrete measure of vintage - the coefficients from ALIVE, perceived health status, the quality of life index, absence of limitations on work/housework/school, absence of social limitations, and mean level of difficulty regressions--are positive and highly statistically significant. This is consistent with the view that vintage is subject to measurement error, which tends to bias the vintage coefficient towards zero, and this bias can be attenuated by grouping prescriptions according to measured vintage.

\footnotetext{
${ }^{27}$ Because poor health and mortality are relatively uncommon at the person level, the fact that sicker people consume more drugs is likely to increase the power of statistical tests performed at the prescription level, where these outcomes are less uncommon.
} 
Estimates reported in the third column are based on the full sample of prescriptions; in this column the vintage of prescriptions of unknown (pre-1939) vintage is assumed to be 1900. As in the first column, vintage is measured as a continuous variable. Notice first that the Rx-price coefficient is much smaller in column 3 than it is in the first two columns. That is because the Rx-price/vintage frontier is quite nonlinear-it is much steeper for vintages greater than 1970 than it is for older vintages - and the sample on which column 3 estimates are based include more old drugs. This estimate implies that, when all drugs are considered (and the value 1900 is imputed for missing vintages), a one-year increase in vintage increased the price of a 1997 prescription by $\$ 0.35$ (about $1 \%$ ), on average.

The vintage coefficients in seven of the nine health indicator regressions in column 3 are positive and highly significant, suggesting that people who use newer drugs had better post-treatment health than people using older drugs for the same condition, controlling for age, sex, race, marital status, education, income, and insurance coverage. Although the effect of vintage on health is generally insignificant when a continuous vintage measure is used and the sample is restricted to drugs with known (post-1939) vintages (column 1), the effect of vintage on health is generally significant when either a discrete vintage measure is used (column 2) or the sample is not restricted to drugs with known vintages (column 3).

Estimates reported in the fourth column are also based on the full sample of prescriptions and a continuous vintage measure; in this column the vintage of prescriptions of unknown (pre-1939) vintage is assumed to be 1920, rather than 1900. In general, this increases the point estimates of the vintage coefficients: the rate of health improvement with respect to vintage appears to be larger, since the old drugs are assumed to be less old. But the coefficients don't change by an enormous amount, and they remain highly significant, suggesting that our results won't be too sensitive to the choice of imputed value for missing vintages. ${ }^{28}$ Since the t-statistics in column 3 are generally larger than those in column 4, henceforth we will impute 1900 to missing vintages.

\footnotetext{
${ }^{28}$ Since the Rx-price coefficient is also higher in column 4 than it is in column 3, estimates of $\mathrm{dP}_{\mathrm{rX}} / \mathrm{dH}_{\mathrm{POST}}$ $=\left(\mathrm{dP}_{\mathrm{rx}} / \mathrm{dV}\right) / \beta_{1}$ from the two columns will be quite similar.
} 
The fifth and last column of Table 3 presents estimates based on the full sample of prescriptions; in this column the vintage of prescriptions of unknown (pre-1939) vintage is assumed to be 1900 , but a discrete measure of vintage is used. If the vintage is less than or equal to 1970 , it is replaced by the mean vintage of pre-1970 drugs (estimated to be 1930.3), and if the vintage is greater than 1970, it is replaced by the mean vintage of 1971-1997 drugs (1984.6). Once again, many of the vintage coefficients are positive and highly statistically significant. For several health indicators, this specification fits the data better than the previous four specifications (judging by the $\mathrm{t}$ statistic on the vintage coefficient). In light of this, this is the specification (discrete vintage, all observations, set missing vintage $=1900$ ) that we will use in the remainder of this paper.

The estimates reported in Table 3 do not control for pre-treatment health status. In Table 4 we report estimated effects of vintage on health that do control for pretreatment health status, i.e. we report estimates from the "dynamic" equation $\mathrm{H}_{\mathrm{POST}, \mathrm{i}}=\beta_{0}$ $+\beta_{1} V_{i j}+\beta_{2} Z_{i}+\beta_{3} H_{P R E, i}+$ diagnosis effects $+u_{i j}$. Column 2 of Table 4 reports estimates of the short-run effect of vintage on health, $\beta_{1}$, and column 3 reports estimates of the long-run effect, $\left(\beta_{1} /\left(1-\beta_{3}\right)\right)$. For purposes of comparison, we also report in column 1 estimates of $\beta_{1}$ from the "static" model (excluding pre-treatment health); these estimates are also reported in column 5 of Table 3. We also report, for each estimate, the cost of the increase in vintage required to achieve a unit increase in post-treatment health ( $\mathrm{dPrx} / \mathrm{d} \mathrm{H})$, and the implied rate of embodied technical progress.

The first set of estimates is coefficients from ALIVE regressions. Recall that ALIVE $=1$ if the person was alive at the time of the second interview, and $=0$ if the person had died. (In the ALIVE and QUALITY of LIFE regressions, initial health status is measured as pre-treatment PERCEIVED HEALTH STATUS. In all other regressions, initial health status is measured as the lagged (pre-treatment) dependent variable.) Drug vintage has a positive and highly significant coefficient in both the static and dynamic models: people consuming newer drugs during the period were more likely to be alive at the end of the period, whether or not we control for perceived health status at the beginning of the period. The static model implies that the cost of the increase in vintage required to keep the person alive is $\$ 8214$. The short-run and long-run estimates from the 
dynamic model are both about the same as this. This cost seems to be quite low, in comparison with other researchers' estimates of the economic value of a life-year. Murphy and Topel (forthcoming 2002) estimate that the average value of a life-year is $\$ 150,000$. Hence our estimate of the cost of preventing a death is lower than Murphy and Topel's estimate of the value of remaining alive for one month. Prevention of a person's death during the sample period presumably increases her longevity by far more than a month. ${ }^{29}$ The estimated rate of technical change is about $1.2 \%$.

Next we consider the health indicator PERCEIVED HEALTH STATUS (conditional on survival). This variable ranges from 0 , for a person in "poor" health (the lowest state), to 1 for a person in "excellent" health (the highest state). Once again, vintage has a positive and highly significant effect on PERCEIVED HEALTH STATUS in both the static and dynamic models. The static model implies that the cost of the increase in vintage required to increase a person's health from poor to excellent is $\$ 3663$. The short-run estimate from the dynamic model is higher (\$5114), but the long-run effect is lower (\$2273). The fact that the long-run estimate is lower than the static estimate is consistent with the view that people in poor initial health tend to consume newer drugs, so that failure to control for initial health biases the estimates of the effect of vintage on health towards zero, and estimates of the cost of the increase in vintage required to achieve better health away from zero. The rate of embodied technical progress implied by the long-run effect is quite high: $9.3 \%$.

The QUALITY OF LIFE index, estimates of which are presented next in Table 4, is based on both of the previous indicators, and is measured for all persons in the sample, not just survivors. It is equal to zero if the person had died, 0.2 if the person was alive and in poor health, 0.4 if the person was alive and in fair health,..., and 1.0 if the person was alive and in excellent health. The estimates based on this index are fairly similar to the estimates based on PERCEIVED HEALTH STATUS, although the cost of health improvement implied by the long-run estimate is somewhat higher (\$2711 vs. \$2273), and the rate of embodied technical progress lower (6.4\% vs. 9.3\%).

\footnotetext{
${ }^{29}$ In the future, we hope to estimate the increase in life expectancy associated with the vintage-induced increase in survival probability.
} 
The next two indicators--ABSENCE OF ANY LIMITATION WORK/HOUSEWORK/SCHOOL and ABSENCE OF SOCIAL LIMITATIONS—also provide strong support for the pharmaceutical-embodied technical progress hypothesis. People were less likely to experience activity or social limitations if they had consumed newer drugs, conditional on their previous limitations (and the other covariates). The long-run estimate indicates that the cost of preventing an activity limitation is $\$ 1745$, and the annual rate of technical progress with respect to activity limitations is $8.4 \%$.

The next two indicators--PERCEIVED MENTAL HEALTH STATUS and ABSENCE OF COGNITIVE LIMITATIONS—do not show any signs of embodied technical progress: neither the static nor the dynamic estimates of the vintage coefficients are significantly different from zero. With respect to the last indicator--ABSENCE OF LIMITATION IN PHYSICAL FUNCTIONING - the vintage effect is significant in the static model, but not in the dynamic one (i.e., controlling for initial physical limitations). But in addition to this broad (binary) indicator of physical limitations, MEPS provides data on respondents' ability to perform seven specific physical activities (lifting 10 pounds, walking 3 blocks, etc.). ${ }^{30}$ As mentioned earlier, we use this information to compute a composite measure called MEAN LEVEL OF DIFFICULTY. As shown in Table 4, people who consume newer drugs tend to have lower levels of mean difficulty. The long-run estimate indicates that the cost of preventing physical difficulty is $\$ 2479$, and the annual rate of technical progress with respect to physical difficulty is $4.8 \%{ }^{31}$.

The estimates we have presented so far measure, we believe, the average effect of drug vintage on health. In our theoretical discussion we postulated that in reality, this effect may be heterogeneous: the effect of drug vintage on health is greater for people in initially poor health. To test this hypothesis, we estimated eq. (7), which includes both main and interaction vintage and pre-treatment health effects: $H_{P O S T, i}=\beta_{0}+\beta_{1} V_{i j}+\beta_{2} Z_{i}$

\footnotetext{
${ }^{30}$ These variables indicate the degree, as well as the absence or presence, of physical limitation.

${ }^{31}$ In fact, we also estimated models of respondents' ability to perform each of the seven activities separately (not reported). Almost all of the detailed physical activities variables strongly support the existence of pharmaceutical-embodied technical progress. People consuming newer drugs tend to experience greater increases (or smaller declines) in physical ability than peop le consuming older drugs. The average rate of embodied technical progress across all seven activities is about $4 \%$. Since detailed physical limitation indicators (and their mean) provide evidence of embodied technical change while a crude measure does not, it is quite possible that if detailed cognitive limitation indicators were available, they (and their mean) would have provided evidence of embodied technical change.
} 
$+\beta_{3} \mathrm{H}_{\mathrm{PRE}, \mathrm{i}}+\beta_{4}\left(\mathrm{~V}_{\mathrm{ij}} * \mathrm{H}_{\mathrm{PRE}, \mathrm{i}}\right)+$ diagnosis effects $+\mathrm{u}_{\mathrm{ij}}$. In this model, the partial derivative of $\mathrm{H}_{\mathrm{POST}, \mathrm{i}}$ with respect to vintage is $\partial \mathrm{H}_{\mathrm{PRE}, \mathrm{i}} / \partial \mathrm{V}_{\mathrm{ij}}=\left(\beta_{1}+\beta_{4} \mathrm{H}_{\mathrm{PRE}, \mathrm{i}}\right)$. Suppose that $\mathrm{H}_{\mathrm{PRE}, \mathrm{i}}$ $=1$ if person $\mathrm{i}$ is in excellent initial health and $\mathrm{H}_{\mathrm{PRE}, \mathrm{i}}=0$ if person $\mathrm{i}$ is in poor initial health. Then $\partial \mathrm{H}_{\mathrm{PRE}, \mathrm{i}} / \partial \mathrm{V}_{\mathrm{ij}}=\left(\beta_{1}+\beta_{4}\right)$ for the person in excellent initial health and $\partial$ $\mathrm{H}_{\mathrm{PRE}, \mathrm{i}} / \partial \mathrm{V}_{\mathrm{ij}}=\beta_{1}$ for the person in poor initial health. We hypothesize that $\beta_{4}$ is negative and significantly different from zero.

Estimates of models of broad health indicators including interactions between drug vintage and initial health are presented in Table 5. The first column presents estimates of the drug vintage effect for people with the lowest initial health $\left(\mathrm{H}_{\mathrm{PRE}}=0\right)$; the second column presents estimates of the drug vintage effect for people with the highest initial health $\left(\mathrm{H}_{\mathrm{PRE}}=1\right)$; and the third column presents estimates of the difference between these two effects. In general, the estimates are consistent with the "negative interaction" hypothesis. In the case of seven of the nine indicators (ALIVE, PERCEIVED HEALTH STATUS, QUALITY OF LIFE INDEX, ABSENCE OF SOCIAL LIMITATIONS, ABSENCE OF COGNITIVE LIMITATIONS, ABSENCE OF LIMITATION IN PHYSICAL FUNCTIONING, MEAN LEVEL OF DIFFICULTY), the effect of drug vintage on health is positive and significant for people with low initial health, insignificant for people with high initial health, and the difference between these effects is statistically significant. In the case of one of the remaining two indicators (PERCEIVED MENTAL HEALTH STATUS), the effect of drug vintage on health is insignificant for both groups, and in the other case (ABSENCE OF ANY LIMITATION), the effect of drug vintage on health is positive and significant only for people with high initial health, which is somewhat puzzling ${ }^{32}$.

In the theoretical section, we postulated that a way to capture the impact of interim health shocks is to include health utilization. In light of this, we ran regressions using equation (8). Table 6 presents our results. For ease of comparison, we transfer the results obtained from the model without health utilization (namely column 2 of Table 4) to the first column of Table 6. The second column lists estimates for the regressions that include utilization measures, namely number of prescriptions (prescription), number of

\footnotetext{
${ }^{32}$ The fact that our measure of average physical limitation (MEAN LEVEL OF DIFFICULTY) provides evidence in support of our hypothesis convinces us that this broad measure is somewhat lacking in its ability to capture the desired effects.
} 
physician visits (physician), and number of inpatient discharges (hospital). The final three columns of Table 6 display the coefficient estimate, standard error, t-statistic and p-value for each of these three utilization measures in corresponding regressions.

Focusing on the first two columns of Table 6, it is immediately apparent that as hypothesized, the drug vintage coefficient has become less significant across all cases, although the qualitative results remain robust between both specifications: all of the 'original' seven indicators remain positive and significant even with the inclusion of health utilization; ABSENCE OF COGNITIVE LIMITATIONS and ABSENCE OF LIMITATION IN PHYSICAL FUNCTIONING remain positive but are now even more insignificant; last, PERCEIVED MENTAL HEALTH STATUS remains negative but is now significant at $5.6 \%$. In addition, the actual values of the coefficient estimate are smaller under this new specification. This in turn implies a lower rate of technical change and a higher cost of eliminating or alleviating a given limitation.

Turning our attention next to the coefficients of the utilization variables, we notice that they are negative and highly significant in most instances ${ }^{33}$. This validates our conjecture that health utilization variables capture health shocks and consequently shocks affecting 'interim' health status. Another interesting observation is that the number of prescription drugs is by far the most significant among all three health utilization measures. An exception to this norm lies in the regression on ALIVE, where not surprisingly, the number of inpatient discharges (hospital) emerges as the most significant utilization variable affecting post-treatment health status. Finally, in regressions that account for both the interaction term (recall Table 5) as well as health utilization, we obtain results qualitatively similar to those in Table 5, strengthening our claim that people in poor initial health tend to benefit most from pharmaceuticalembodied technical change ${ }^{34}$.

Overall, the evidence suggests that the people in poor initial health tend to benefit most from pharmaceuticalembodied technical change. As the following table shows, the

\footnotetext{
${ }^{33}$ In the specification shown in Table 6, we employ the logarithm of the utilization variables in order to highlight the negative relationship between them and each dependent (health status) variable. Our estimates remain robust to alternative specifications of these utilization variables, including one in which they were introduced as class variables, as well as a linear specification.

${ }^{34} \mathrm{We}$ do not present these results as they are also quantitatively close to those reported in Table 5.
} 
health of people with low levels of education (hence low skills and income) tends to be worse than the health of people with more education. ${ }^{35}$

\begin{tabular}{|l|l|l|l|}
\hline Type of limitation & $\begin{array}{l}\text { Overall rate }(\% \\
\text { of people } \\
\text { experiencing } \\
\text { limitation) }\end{array}$ & $\begin{array}{l}\text { Less-than- } \\
\text { high-school } \\
\text { rate minus } \\
\text { high-school } \\
\text { rate }\end{array}$ & $\begin{array}{l}\text { More-than- } \\
\text { high-school } \\
\text { rate minus } \\
\text { high-school } \\
\text { rate }\end{array}$ \\
\hline $\begin{array}{l}\text { ANY LIMITATION } \\
\text { WORK/HOUSEWORK/SCHOOL }\end{array}$ & $8.3 \%$ & $6.0 \%$ & $-3.5 \%$ \\
\hline $\begin{array}{l}\text { LIMITATION IN PHYSICAL } \\
\text { FUNCTIONING }\end{array}$ & 9.4 & 4.9 & -2.7 \\
\hline SOCIAL LIMITATIONS & 4.6 & 2.9 & -1.2 \\
\hline COGNITIVE LIMITATIONS & 3.2 & 3.3 & -1.3 \\
\hline
\end{tabular}

Hence pharmaceuticatembodied technical change may have a tendency to reduce inequality as well as promote economic growth, broadly defined.

\section{Summary and conclusions}

For sustained economic growth to occur, technological progress is necessary. There are two kinds of technical progress—disembodied and embodied — and both kinds are driven by research and development. A number of econometric studies have concluded that technical progress embodied in equipment is a major source of manufacturing productivity growth.

Other recent research has suggested that, over the long run, growth in the U.S. economy's "health output" has been at least as large as the growth in non-health goods and services. Moreover, one important input in the production of healthpharmaceuticals-is even more R\&D-intensive than equipment.

In this paper we have tested the pharmaceuticalembodied technical progress hypothesis - the hypothesis that newer drugs increase the length and quality of life-and estimated the rate of progress. To do this, we estimated health production functions, in which the dependent variables are various indicators of post-treatment health status (such as survival, perceived health status, and presence of physical or cognitive limitations),

\footnotetext{
${ }^{35}$ The reported differences in rates are adjusted for age, sex, race, marital status, and insurance coverage.
} 
and the regressors include drug vintage (the year in which the FDA first approved a drug's active ingredient(s)) and indicators of pre-treatment health status. We estimated these relationships using extremely disaggregated-prescription-level—cross-sectional data derived primarily from the 1997 Medical Expenditure Panel Survey.

We found that people who used newer drugs had better post-treatment health than people using older drugs for the same condition, controlling for pre-treatment health, age, sex, race, marital status, education, income, and insurance coverage.

- Survival. People consuming newer drugs during the period were more likely to be alive at the end of the period, whether or not we control for perceived health status at the beginning of the period. The estimates imply that the cost of the increase in vintage required to keep the person alive is $\$ 8214$. This cost seems quite low, in comparison with other researchers' estimates of the economic value of a life-year: our estimate of the cost of preventing a death is lower than Murphy and Topel's estimate of the value of remaining alive for one month.

- Perceived health status. Vintage has a positive and highly significant effect on perceived health status and a quality of life index whether or not we control for perceived health status at the beginning of the period. The rate of embodied technical progress implied by the long-run effect is quite high: $9.3 \%$.

- Activity or social limitations. People were less likely to experience activity or social limitations if they had consumed newer drugs, conditional on their previous limitations (and the other covariates). The long-run estimate indicates that the cost of preventing an activity limitation is $\$ 1745$, and the annual rate of technical progress with respect to activity limitations is $8.4 \%$.

- Physical limitations. Almost all of the seven detailed physical functioning variables (lifting 10 pounds, walking 3 blocks, etc.) reflect the existence of pharmaceuticalembodied technical progress. People consuming newer drugs tend to experience greater increases (or smaller declines) in physical ability than people consuming older drugs. The average rate of embodied technical progress across all seven activities is about $4 \%$.

In addition, we test an alternative model which accounts for health shocks experienced during the period (between pre- and post- treatment health status), by using 
health utilization measures such as the number of prescriptions, physician visits, and inpatient discharges, as indicators of these shocks. As postulated, we find these utilization variables are negatively related to post-treatment health status. While the drug vintage estimates from this new specification are smaller and less significant than in the model without health utilization, our qualitative results are unchanged. We argue that this does not necessarily imply that impact of drug vintage is less - adjusting for utilization simply decomposes the drug vintage coefficient into its direct and indirect (via utilization variables) effects.

Last, most of the health measures indicate that the effect of drug vintage on health is positive and significant for people with low initial health and insignificant for people with high initial health, and that the difference between these effects is statistically significant. This suggests that the people in poor initial health tend to benefit most from pharmaceuticalembodied technical change. The health of people with low levels of education (hence low skills and income) tends to be worse than the health of people with more education. Hence, in contrast to equipment-embodied technical progress, which tends to increase economic inequality, pharmaceutical-embodied technical progress has a tendency to reduce inequality as well as promote economic growth, broadly defined. 


\section{References}

Anderson, R. N. (1999), United States life tables, 1997. National vital statistics reports; vol 47 no. 28. Hyattsville, Maryland: National Center for Health Statistics.

Bahk, Byong-Hyong and Michael Gort (1993), "Decomposing Learning by Doing in New Plants", Journal of Political Economy, 101, 561-583.

Bartel, Ann, and Frank Lichtenberg (1987), "The Comparative Advantage of Educated Workers in Implementing New Technology," Review of Economics and Statistics 69(1), February, 1-11.

(1991), "The Age of Technology and Its Impact on

Employee Wages," Economics of Innovation and New Technology 1, 215-31.

Fisher, Franklin M., "Embodied Technical Change and the Existence of an Aggregate Capital Stock," The Review of Economic Studies, Vol. 32, No. 4. (Oct., 1965), pp. 263288.

Folland, Sherman, Allen Goodman and Miron Stano, The Economics of Health and Health Care, third edition (Upper Saddle River, NJ: Prentice Hall, 2001).

Griliches, Zvi, and Frank Lichtenberg (1984), "R\&D and Productivity at the Industry Level: Is There Still a Relationship?," in $R \& D$, Patents, and Productivity, Zvi Griliches, ed. (Chicago: Univ. of Chicago Press).

Hobijn, Bart (2001), “Embodiment in U.S. Manufacturing,” working paper, Federal Reserve Bank of New York, March 2001.

Hulten, Charles R., "Growth Accounting When Technical Change is Embodied in Capital," The American Economic Review, Vol. 82, No. 4. (Sep., 1992), pp. 964-980.

Jones, Charles I. (1998), Introduction to Economic Growth(New York: Norton).

Lichtenberg, Frank (2001), "Are the Benefits of Newer Drugs Worth Their Cost?

Evidence from the 1996 MEPS," Health Affairs 20(5), September/October, pp. 241-51.

Lichtenberg, Frank, and Donald Siegel (1991), "The Impact of R\&D Investment on Productivity: New Evidence Using Linked R\&D-LRD Data," with Donald Siegel, Economic Inquiry 29 (April), 203-28.

Lleras-Muney, Adriana, and Frank Lichtenberg (2002), “The Effect of Education on Medical Technology Adoption: Are the More Educated More Likely to Use New Drugs?," NBER Working Paper No. 9185, Sept. 2002. 
Murphy, Kevin, and Robert Topel (2002), “The Economic Value of Medical Research," in The Value of Medical Research, ed. by Kevin Murphy and Robert Topel (University of Chicago Press, forthcoming).

Nordhaus, William D. (2002), "The Health of Nations: The Contribution of Improved Health to Living Standards," NBER Working Paper No. 8818, February; forthcoming in The Value of Medical Research, ed. by Kevin Murphy and Robert Topel (University of Chicago Press).

Romer, Paul (1990), "Endogenous Technological Change," Journal of Political Economy 98 (October), S71-S102.

Sakellaris, Plutarchos and Dan Wilson (2000), "The Production-Side Approach to Estimating Embodied Technological Change," mimeo.

Solow, Robert M. (1956), "A Contribution to the Theory of Economic Growth," Quarterly Journal of Economics 70 (February), 65-94.

, "The Production Function and the Theory of Capital," Review of Economic Studies, Volume XXIII (1955-56), pp. 101-108.

-------------, "Investment and Technical Progress," Chapter 7 in Mathematical Methods in the Social Sciences, 1959 (K. J. Arrow, S. Karlin, and P. Suppes, eds.), Stanford University Press, 1960.

------------, “Technical Progress, Capital Formation, and Economic Growth,”

The American Economic Review, Vol. 52, No. 2, Papers and Proceedings of the SeventyFourth Annual Meeting of the American Economic Association. (May, 1962), pp. 76-86.

-------------, Capital Theory and the Rate of Return, (Professor F. de Vries Lectures), Amsterdam, North Holland, 1963.

, "Capital, Labor, and Income in Manufacturing," Conference in Income and Wealth, The Behavior of Income Shares, Princeton University Press, 1964, pp. 101-128.

Wald, A. (1940), "The Fitting of Straight Lines if Both Variables are Subject to Error," Annals of Mathematical Statistics 11, 284-300.

Wells, Kenneth B., et al (1996), Caring for Depression (Cambridge MA: Harvard University Press).

Wennberg, John E. et al (1980) A Small Area Approach to the Analysis of Health System Performance, U.S. Dept. of Health and Human Services, Public Health Service, Health Resources Administration, Bureau of Health Planning; Washington, D.C. 


\section{Figure 1}

Industrial R\&D funds as a percent of net sales in

R\&D- performing companies, 1997

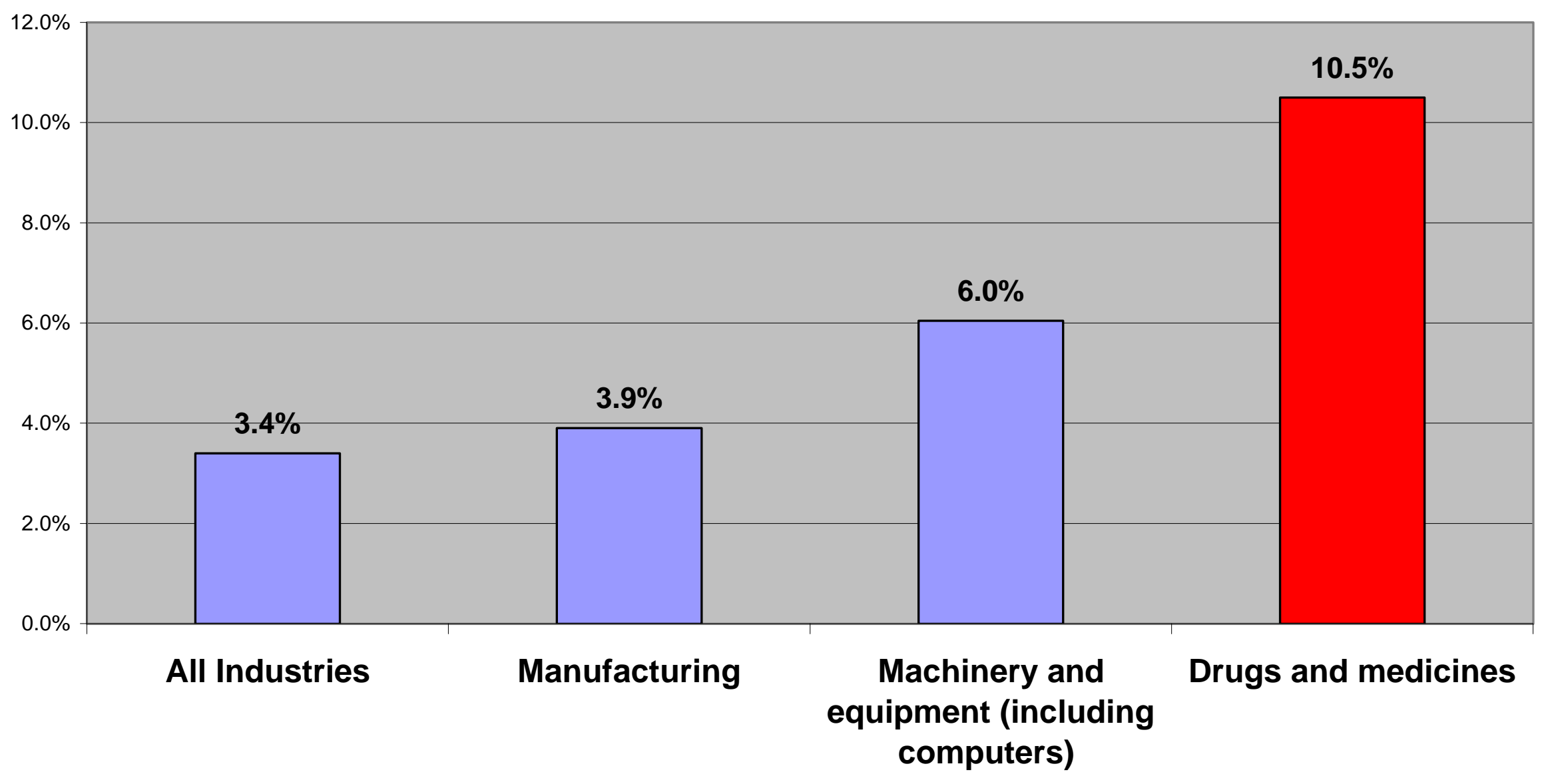

Source: http://caspar.nsf.gov/nsf/srs/IndRD/NSF\%2001\%2D305/A-21.xls 
Figure 2

Negative interaction between vintage and initial health

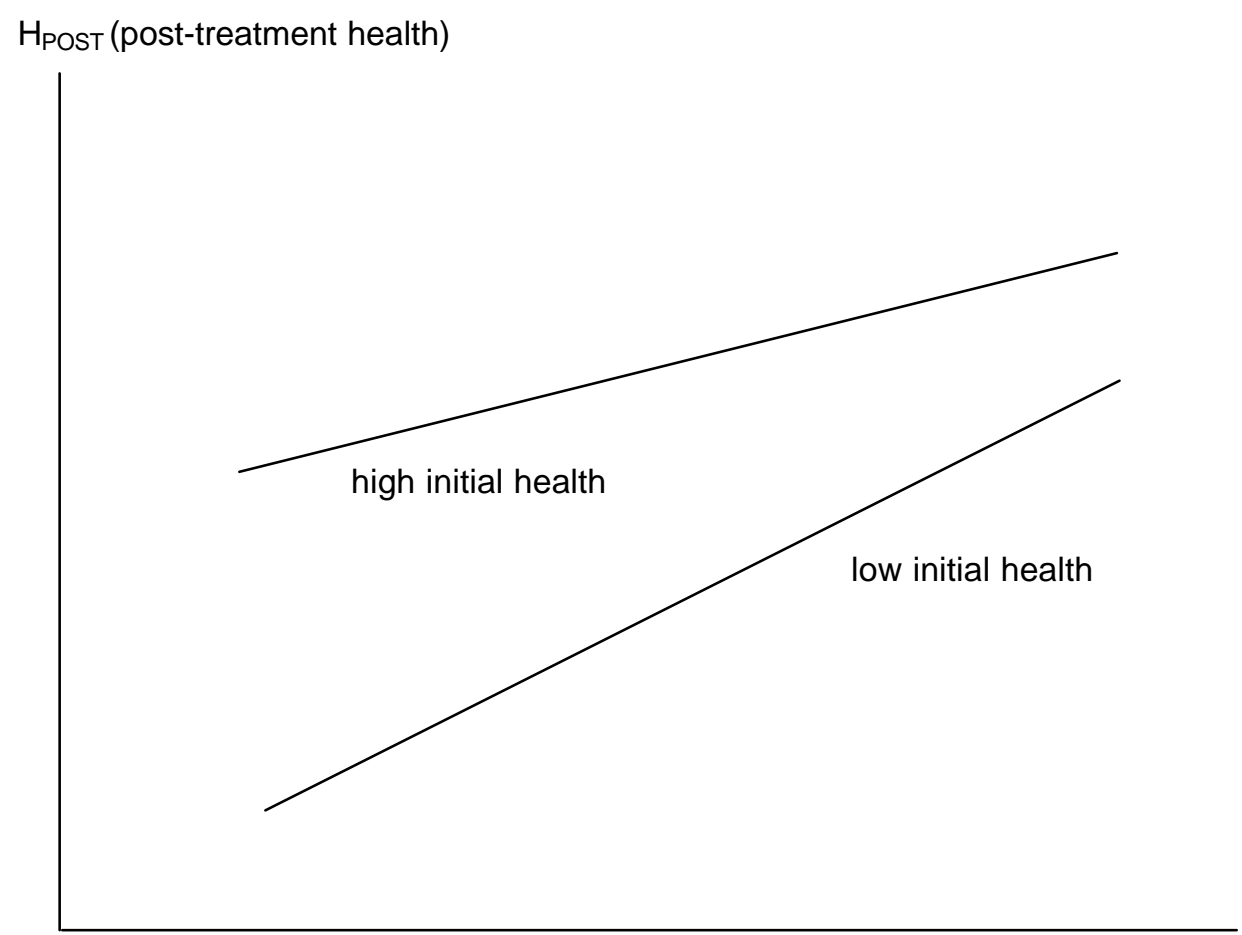

vintage 
Figure 3

Time line of MEPS interviews and prescribed medicine events

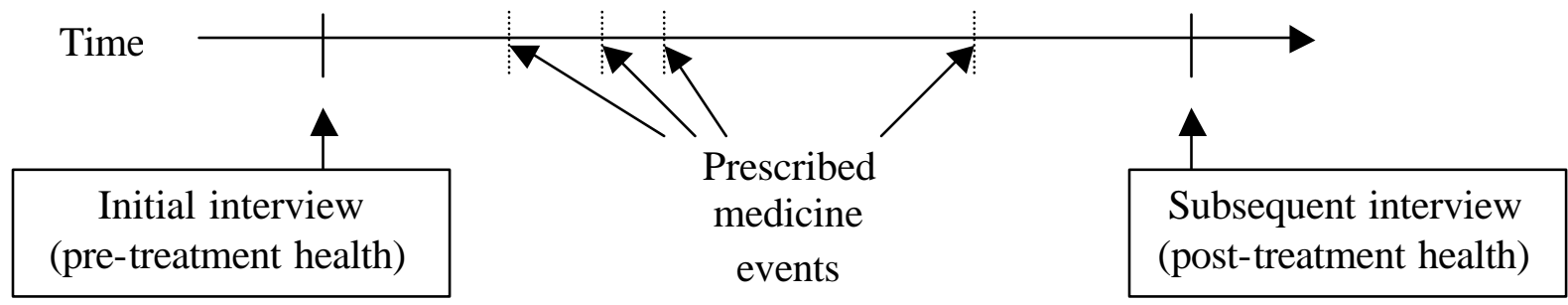


Figure 4

Number of new molecular entities approved each year, according to two different lists provided by the FDA

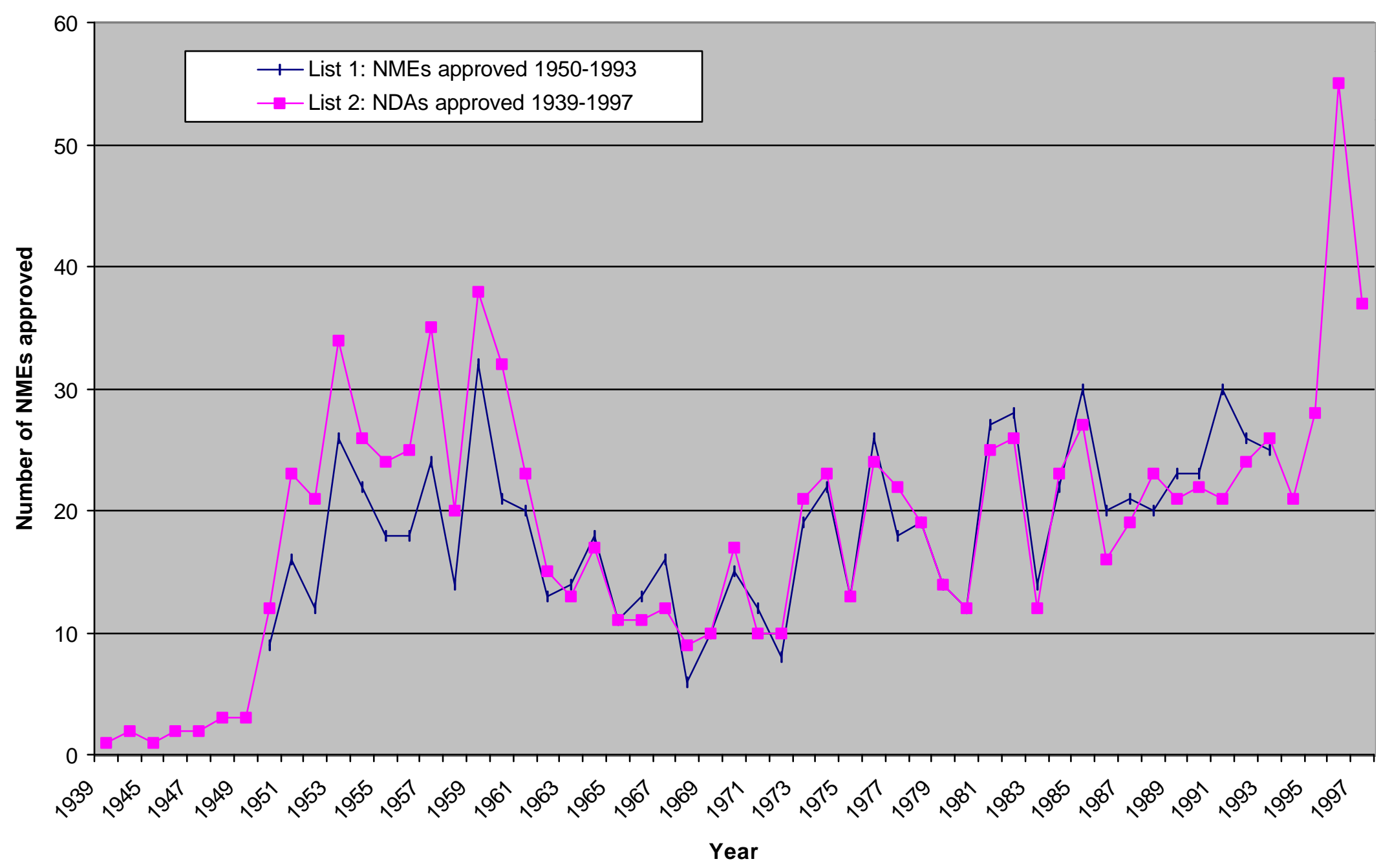


Table 1

Table 1

Top 20 active ingredients, ranked by number of prescriptions, in the 1997 MEPS

\begin{tabular}{|r|l|r|r|r|}
\hline rank & active_ingredient & vintage & $\begin{array}{l}\text { MEPS } \\
\text { prescriptions }\end{array}$ & $\begin{array}{l}\text { cumulative \% } \\
\text { of 1997 MEPS } \\
\text { prescriptions }\end{array}$ \\
\hline 1 & acetaminophen & pre-1939 & 7438 & $3.1 \%$ \\
\hline 2 & conjugated estrogens & 1942 & 5671 & $5.4 \%$ \\
\hline 3 & hydrochlorothiazide & 1959 & 5389 & $7.7 \%$ \\
\hline 4 & amoxicillin (as trihydrate) & 1973 & 5084 & $9.8 \%$ \\
\hline 5 & levothyroxine sodium & pre-1939 & 4938 & $11.8 \%$ \\
\hline 6 & ethinyl estradiol & 1968 & 3840 & $13.4 \%$ \\
\hline 7 & albuterol & 1981 & 3807 & $15.0 \%$ \\
\hline 8 & furosemide & 1966 & 3643 & $16.5 \%$ \\
\hline 9 & hydrocodone bitartrate & pre-1939 & 3298 & $17.9 \%$ \\
\hline 10 & potassium chloride & pre-1939 & 2911 & $19.1 \%$ \\
\hline 11 & medroxyprogesterone acetate & 1959 & 2871 & $20.3 \%$ \\
\hline 12 & digoxin & 1954 & 2823 & $21.4 \%$ \\
\hline 13 & lisinopril & 1987 & 2822 & $22.6 \%$ \\
\hline 14 & atenolol & 1981 & 2794 & $23.8 \%$ \\
\hline 15 & nifedipine & 1981 & 2686 & $24.9 \%$ \\
\hline 16 & triamterene & 1964 & 2383 & $25.9 \%$ \\
\hline 17 & ibuprofen & 1974 & 2360 & $26.8 \%$ \\
\hline 18 & guaifenesin & pre-1939 & 2303 & $27.8 \%$ \\
\hline 19 & diltiazem hydrochloride & 1982 & 2254 & $28.7 \%$ \\
\hline 20 & enalapril maleate & 1985 & 2207 & $29.6 \%$ \\
\hline
\end{tabular}


Table 2

Sample means: person-level vs. prescription-level

\begin{tabular}{|l|r|r|}
\hline & $\begin{array}{l}\text { person-level mean } \\
(\mathrm{n}=34 \mathrm{~K})\end{array}$ & $\begin{array}{l}\text { rx-level mean } \\
(\mathrm{n}=156 \mathrm{~K})\end{array}$ \\
\hline AGE & 33.8 & 53.7 \\
\hline COMPLETED YEARS OF EDUCATION & 10.4 & 11.3 \\
\hline male & $47.5 \%$ & $37.7 \%$ \\
\hline white & $79.7 \%$ & $84.4 \%$ \\
\hline medicaid & $18.7 \%$ & $22.2 \%$ \\
\hline medicare & $13.5 \%$ & $42.7 \%$ \\
\hline any private insurance & $63.9 \%$ & $63.6 \%$ \\
\hline any public insurance & $20.3 \%$ & $30.5 \%$ \\
\hline uninsured & $15.8 \%$ & $5.8 \%$ \\
\hline alive & $99.7 \%$ & $99.2 \%$ \\
\hline $\begin{array}{l}\text { ABSENCE OF ANY LIMITATION } \\
\text { WORK/HOUSEWORK/SCHOOL }\end{array}$ & $91.7 \%$ & $68.1 \%$ \\
\hline ABSENCE OF LIMITATION IN PHYSICAL & & \\
FUNCTIONING & $90.6 \%$ & $64.1 \%$ \\
\hline ABSENCE OF SOCIAL LIMITATIONS & $95.4 \%$ & $81.1 \%$ \\
\hline ABSENCE OF COGNITIVE LIMITATIONS & $96.8 \%$ & $87.6 \%$ \\
\hline PERCEIVED HEALTH STATUS & $69.6 \%$ & $47.1 \%$ \\
\hline PERCEIVED MENTAL HEALTH STATUS & $76.4 \%$ & $64.7 \%$ \\
\hline
\end{tabular}


Table 3

Estimates of drug vintage coefficients from alternative models that do not control for initial health

\begin{tabular}{|l|c|c|c|c|c|}
\hline column & 1 & 2 & 3 & 4 & 5 \\
\hline initial health? & no & no & no & no & no \\
\hline missing vintages & excluded & excluded & $\begin{array}{c}\text { included, set } \\
\text { missing=1900 }\end{array}$ & $\begin{array}{c}\text { included, set } \\
\text { missing=1920 }\end{array}$ & $\begin{array}{c}\text { included, set } \\
\text { missing=1900 }\end{array}$ \\
\hline continuous or discrete vintage & continuous & discrete & continuous & continuous & discrete \\
\hline approx. no. of observations & $104 \mathrm{~K}$ & $104 \mathrm{~K}$ & $130 \mathrm{~K}$ & $130 \mathrm{~K}$ & $130 \mathrm{~K}$ \\
\hline
\end{tabular}

$\underline{\text { Rx Price (mean }=\$ 38.95)}$

\begin{tabular}{|l|c|c|c|c|c|}
\hline \hline vintage coefficient & 1.245 & 1.213 & 0.347 & 0.502 & 0.542 \\
\hline standard error & 0.011 & 0.013 & 0.005 & 0.007 & 0.006 \\
\hline $\mathrm{t}$-stat & 113.83 & 96.92 & 67.91 & 76.62 & 87.2 \\
\hline $\mathrm{p}$-value & $<.0001$ & $<.0001$ & $<.0001$ & $<.0001$ & $<.0001$ \\
\hline
\end{tabular}

ALIVE (mean=0.992)

\begin{tabular}{|l|c|c|c|c|c|}
\hline vintage coefficient & $2.80 \mathrm{E}-05$ & $5.70 \mathrm{E}-05$ & $6.20 \mathrm{E}-05$ & $7.90 \mathrm{E}-05$ & $6.60 \mathrm{E}-05$ \\
\hline standard error & $2.10 \mathrm{E}-05$ & $2.40 \mathrm{E}-05$ & $8.18 \mathrm{E}-06$ & $1.10 \mathrm{E}-05$ & $1.00 \mathrm{E}-05$ \\
\hline $\mathrm{t}$-stat & 1.34 & 2.43 & 7.58 & 7.46 & 6.52 \\
\hline p-value & 0.1792 & 0.0152 & $<.0001$ & $<.0001$ & $<.0001$ \\
\hline
\end{tabular}

PERCEIVED HEALTH STATUS (mean $\mathbf{0} \mathbf{0 . 4 7 6}$ )

\begin{tabular}{|l|c|c|c|c|c|}
\hline vintage coefficient & $-4.00 \mathrm{E}-05$ & $2.36 \mathrm{E}-04$ & $1.14 \mathrm{E}-04$ & $1.32 \mathrm{E}-04$ & $1.48 \mathrm{E}-04$ \\
\hline standard error & $6.50 \mathrm{E}-05$ & $7.30 \mathrm{E}-05$ & $2.40 \mathrm{E}-05$ & $3.20 \mathrm{E}-05$ & $3.00 \mathrm{E}-05$ \\
\hline $\mathrm{t}$-stat & -0.62 & 3.23 & 4.64 & 4.2 & 4.93 \\
\hline $\mathrm{p}$-value & 0.5364 & 0.0013 & $<.0001$ & $<.0001$ & $<.0001$ \\
\hline
\end{tabular}

QUALITY OF LIFE INDEX (mean= 0.576)

\begin{tabular}{|l|c|c|c|c|c|}
\hline vintage coefficient & $-3.99 \mathrm{E}-06$ & $2.29 \mathrm{E}-04$ & $1.15 \mathrm{E}-04$ & $1.38 \mathrm{E}-04$ & $1.49 \mathrm{E}-04$ \\
\hline standard error & $5.30 \mathrm{E}-05$ & $5.90 \mathrm{E}-05$ & $2.00 \mathrm{E}-05$ & $2.50 \mathrm{E}-05$ & $2.40 \mathrm{E}-05$ \\
\hline $\mathrm{t}-\mathrm{stat}$ & -0.08 & 3.87 & 5.81 & 5.40 & 6.11 \\
\hline $\mathrm{p}$-value & 0.9394 & 0.0001 & $<.0001$ & $<.0001$ & $<.0001$ \\
\hline
\end{tabular}

ABSENCE OF ANY LIMITATION WORK/HOUSEWRK/SCHL (mean = 0.687)
\begin{tabular}{|l|c|c|c|c|c|}
\hline vintage coefficient & $9.00 \mathrm{E}-05$ & $5.20 \mathrm{E}-04$ & $1.58 \mathrm{E}-04$ & $1.97 \mathrm{E}-04$ & $2.78 \mathrm{E}-04$ \\
\hline standard error & $1.00 \mathrm{E}-04$ & $1.13 \mathrm{E}-04$ & $3.80 \mathrm{E}-05$ & $4.80 \mathrm{E}-05$ & $4.60 \mathrm{E}-05$ \\
\hline t-stat & 0.89 & 4.59 & 4.19 & 4.07 & 6.01 \\
\hline p-value & 0.3712 & $<.0001$ & $<.0001$ & $<.0001$ & $<.0001$ \\
\hline
\end{tabular}

ABSENCE OF SOCIAL LIMITATIONS (mean $=\mathbf{0 . 8 1 7}$ )
\begin{tabular}{|l|c|c|c|c|c|}
\hline vintage coefficient & $2.90 \mathrm{E}-04$ & $6.60 \mathrm{E}-04$ & $9.10 \mathrm{E}-05$ & $1.22 \mathrm{E}-04$ & $2.38 \mathrm{E}-04$ \\
\hline standard error & $9.10 \mathrm{E}-05$ & $1.02 \mathrm{E}-04$ & $3.40 \mathrm{E}-05$ & $4.40 \mathrm{E}-05$ & $4.20 \mathrm{E}-05$ \\
\hline t-stat & 3.2 & 6.48 & 2.68 & 2.79 & 5.7 \\
\hline p-value & 0.0014 & $<.0001$ & 0.0075 & 0.0053 & $<.0001$ \\
\hline
\end{tabular}

Note: Each vintage coefficient is estimated from a separate regression of the form $\mathrm{H}_{\mathrm{POST}, \mathrm{i}}=\beta_{0}+\beta_{1}$ $\mathrm{V}_{\mathrm{ij}}+\beta_{2} \mathrm{Z}_{\mathrm{i}}+$ diagnosis effects $+\mathrm{u}_{\mathrm{ij}}$. All models include the following person-level covariates: age, sex, race, education, income, marital status, and indicators of insurance coverage. 
Table 3 (continued)

Estimates of drug vintage coefficients from alternative models that do not control for initial health

\begin{tabular}{|l|c|c|c|c|c|}
\hline column & 1 & 2 & 3 & 4 & 5 \\
\hline initial health? & no & no & no & no & no \\
\hline missing vintages & excluded & excluded & $\begin{array}{c}\text { included, set } \\
\text { missing=1900 }\end{array}$ & $\begin{array}{c}\text { included, set } \\
\text { missing=1920 }\end{array}$ & $\begin{array}{c}\text { included, set } \\
\text { missing=1900 }\end{array}$ \\
\hline continuous or discrete vintage & continuous & discrete & continuous & continuous & discrete \\
\hline approx. no. of observations & $104 \mathrm{~K}$ & $104 \mathrm{~K}$ & $130 \mathrm{~K}$ & $130 \mathrm{~K}$ & $130 \mathrm{~K}$ \\
\hline
\end{tabular}

PERCEIVED MENTAL HEALTH STATUS (mean $\mathbf{0} \mathbf{0 . 6 2 9}$ )

\begin{tabular}{|l|c|c|c|c|c|}
\hline vintage coefficient & $-1.10 \mathrm{E}-04$ & $-9.00 \mathrm{E}-05$ & $1.00 \mathrm{E}-05$ & $7.17 \mathrm{E}-06$ & $-8.91 \mathrm{E}-06$ \\
\hline standard error & $6.40 \mathrm{E}-05$ & $7.20 \mathrm{E}-05$ & $2.40 \mathrm{E}-05$ & $3.10 \mathrm{E}-05$ & $2.90 \mathrm{E}-05$ \\
\hline $\mathrm{t}$-stat & -1.81 & -1.26 & 0.43 & 0.23 & -0.3 \\
\hline$p$-value & 0.071 & 0.2086 & 0.6701 & 0.8166 & 0.7626 \\
\hline
\end{tabular}

ABSENCE OF COGNITIVE LIMITATIONS (mean $=0.878$ )

\begin{tabular}{|l|c|c|c|c|c|}
\hline vintage coefficient & $-9.00 \mathrm{E}-05$ & $1.20 \mathrm{E}-05$ & $2.40 \mathrm{E}-05$ & $2.40 \mathrm{E}-05$ & $3.60 \mathrm{E}-05$ \\
\hline standard error & $7.60 \mathrm{E}-05$ & $8.60 \mathrm{E}-05$ & $2.80 \mathrm{E}-05$ & $3.70 \mathrm{E}-05$ & $3.50 \mathrm{E}-05$ \\
\hline $\mathrm{t}$-stat & -1.17 & 0.14 & 0.85 & 0.64 & 1.03 \\
\hline$p$-value & 0.2435 & 0.8876 & 0.3951 & 0.5216 & 0.3015 \\
\hline
\end{tabular}

ABSENCE OF LIMITATION IN PHYSICAL FUNCTIONING (mean = 0.672)
\begin{tabular}{|l|c|c|c|c|c|}
\hline vintage coefficient & $-9.00 \mathrm{E}-05$ & $1.90 \mathrm{E}-04$ & $1.64 \mathrm{E}-04$ & $1.87 \mathrm{E}-04$ & $1.60 \mathrm{E}-04$ \\
\hline standard error & $1.04 \mathrm{E}-04$ & $1.17 \mathrm{E}-04$ & $3.90 \mathrm{E}-05$ & $5.00 \mathrm{E}-05$ & $4.80 \mathrm{E}-05$ \\
\hline $\mathrm{t}$-stat & -0.86 & 1.62 & 4.23 & 3.74 & 3.36 \\
\hline p-value & 0.3893 & 0.1053 & $<.0001$ & 0.0002 & 0.0008 \\
\hline
\end{tabular}

MEAN LEVEL OF DIFFICULTY (mean $\mathbf{0} \mathbf{0 . 8 3 7}$ )

\begin{tabular}{|l|c|c|c|c|c|}
\hline vintage coefficient & $6.30 \mathrm{E}-05$ & $1.95 \mathrm{E}-04$ & $1.25 \mathrm{E}-04$ & $1.54 \mathrm{E}-04$ & $1.39 \mathrm{E}-04$ \\
\hline standard error & $5.90 \mathrm{E}-05$ & $6.60 \mathrm{E}-05$ & $2.20 \mathrm{E}-05$ & $2.80 \mathrm{E}-05$ & $2.70 \mathrm{E}-05$ \\
\hline $\mathrm{t}$-stat & 1.07 & 2.95 & 5.68 & 5.43 & 5.15 \\
\hline $\mathrm{p}$-value & 0.2852 & 0.0032 & $<.0001$ & $<.0001$ & $<.0001$ \\
\hline
\end{tabular}

Note: Each vintage coefficient is estimated from a separate regression of the form $\mathrm{H}_{\mathrm{POST}, \mathrm{i}}=\beta_{0}+\beta_{1}$ $\mathrm{V}_{\mathrm{ij}}+\beta_{2} \mathrm{Z}_{\mathrm{i}}+$ diagnosis effects $+\mathrm{u}_{\mathrm{ij}}$. All models include the following person-level covariates: age, sex, race, education, income, marital status, and indicators of insurance coverage. 
Table 4

Broad health indicators

Estimates of drug vintage coefficients from models excluding and including controls for initial health

\begin{tabular}{|l|c|c|c|}
\hline column & 1 & 2 & 3 \\
\hline initial health? & no & yes & yes \\
\hline & & $\begin{array}{c}\text { short-run effect } \\
\left(\beta_{1}\right)\end{array}$ & $\begin{array}{c}\text { long-run effect } \\
\left(\beta_{1} /\left(1-\beta_{3}\right)\right)\end{array}$ \\
\hline
\end{tabular}

ALIVE (mean=0.992)

\begin{tabular}{|l|c|c|c|}
\hline \hline vintage coefficient & $6.60 \mathrm{E}-05$ & $6.40 \mathrm{E}-05$ & $6.51 \mathrm{E}-05$ \\
\hline standard error & $1.00 \mathrm{E}-05$ & $1.00 \mathrm{E}-05$ & \\
\hline $\mathrm{t}$-stat & 6.52 & 6.38 & \\
\hline $\mathrm{p}-\mathrm{value}$ & $<.0001$ & $<.0001$ & \\
\hline $\mathrm{dPrx} / \mathrm{d} \mathrm{H}$ & $\$ 8,214$ & $\$ 8,470$ & $\$ 8,325$ \\
\hline rate of tech change & $1.2 \%$ & $1.2 \%$ & $1.2 \%$ \\
\hline
\end{tabular}

PERCEIVED HEALTH STATUS (mean $\mathbf{= 0 . 4 7 6 )}$

\begin{tabular}{|l|c|c|c|}
\hline vintage coefficient & $1.48 \mathrm{E}-04$ & $1.06 \mathrm{E}-04$ & $2.38 \mathrm{E}-04$ \\
\hline standard error & $3.00 \mathrm{E}-05$ & $2.50 \mathrm{E}-05$ & \\
\hline $\mathrm{t}$-stat & 4.93 & 4.27 & \\
\hline $\mathrm{p}$-value & $<.0001$ & $<.0001$ & \\
\hline $\mathrm{dPrx} / \mathrm{d} \mathrm{H}$ & $\$ 3,663$ & $\$ 5,114$ & $\$ 2,273$ \\
\hline rate of tech change & $5.8 \%$ & $4.1 \%$ & $9.3 \%$ \\
\hline
\end{tabular}

QUALITY OF LIFE INDEX (mean= 0.576)

\begin{tabular}{|l|c|c|c|}
\hline \hline vintage coefficient & $1.49 \mathrm{E}-04$ & $1.10 \mathrm{E}-04$ & $2.00 \mathrm{E}-04$ \\
\hline standard error & $2.40 \mathrm{E}-05$ & $2.00 \mathrm{E}-05$ & \\
\hline $\mathrm{t}$-stat & 6.11 & 5.49 & \\
\hline $\mathrm{p}$-value & $<.0001$ & $<.0001$ & \\
\hline $\mathrm{dPrx} / \mathrm{d} \mathrm{H}$ & $\$ 3,638$ & $\$ 4,928$ & $\$ 2,711$ \\
\hline rate of tech change & $4.8 \%$ & $3.5 \%$ & $6.4 \%$ \\
\hline
\end{tabular}

ABSENCE OF ANY LIMITATION WORK/HOUSEWRK/SCHL $($ mean $=\mathbf{0 . 6 8 7}$ )
\begin{tabular}{|l|c|c|c|}
\hline vintage coefficient & $2.78 \mathrm{E}-04$ & $1.56 \mathrm{E}-04$ & $3.11 \mathrm{E}-04$ \\
\hline standard error & $4.60 \mathrm{E}-05$ & $4.10 \mathrm{E}-05$ & \\
\hline $\mathrm{t}$-stat & 6.01 & 3.85 & \\
\hline $\mathrm{p}$-value & $<.0001$ & 0.0001 & \\
\hline $\mathrm{dPrx} / \mathrm{d} \mathrm{H}$ & $\$ 1,950$ & $\$ 3,475$ & $\$ 1,745$ \\
\hline rate of tech change & $7.5 \%$ & $4.2 \%$ & $8.4 \%$ \\
\hline
\end{tabular}

ABSENCE OF SOCIAL LIMITATIONS (mean $=\mathbf{0 . 8 1 7 )}$
\begin{tabular}{|l|c|c|c|}
\hline \hline vintage coefficient & $2.38 \mathrm{E}-04$ & $1.37 \mathrm{E}-04$ & $2.14 \mathrm{E}-04$ \\
\hline standard error & $4.20 \mathrm{E}-05$ & $3.90 \mathrm{E}-05$ & \\
\hline $\mathrm{t}$-stat & 5.7 & 3.53 & \\
\hline $\mathrm{p}$-value & $<.0001$ & 0.0004 & \\
\hline $\mathrm{dPrx} / \mathrm{d} \mathrm{H}$ & $\$ 2,278$ & $\$ 3,957$ & $\$ 2,535$ \\
\hline rate of tech change & $5.4 \%$ & $3.1 \%$ & $4.8 \%$ \\
\hline
\end{tabular}


Table 4 (continued)

Broad health indicators

Estimates of drug vintage coefficients from models excluding and including controls for initial health

\begin{tabular}{|l|c|c|c|}
\hline column & 1 & 2 & 3 \\
\hline initial health? & no & yes & yes \\
\hline & & $\begin{array}{c}\text { short-run effect } \\
\left(\beta_{1}\right)\end{array}$ & $\begin{array}{c}\text { long-run effect } \\
\left(\beta_{1} /\left(1-\beta_{3}\right)\right)\end{array}$ \\
\hline
\end{tabular}

\section{PERCEIVED MENTAL HEALTH STATUS (mean $\mathbf{0} \mathbf{0 . 6 2 9}$ )}

\begin{tabular}{|l|c|c|c|}
\hline vintage coefficient & $-8.91 \mathrm{E}-06$ & $-3.00 \mathrm{E}-05$ & $-6.44 \mathrm{E}-05$ \\
\hline standard error & $2.90 \mathrm{E}-05$ & $2.60 \mathrm{E}-05$ & \\
\hline $\mathrm{t}$-stat & -0.3 & -1.1 & \\
\hline p-value & 0.7626 & 0.271 & \\
\hline
\end{tabular}

ABSENCE OF COGNITIVE LIMITATIONS (mean $\mathbf{0} \mathbf{0 . 8 7 8 )}$

\begin{tabular}{|l|c|c|c|}
\hline vintage coefficient & $3.60 \mathrm{E}-05$ & $1.70 \mathrm{E}-05$ & $4.06 \mathrm{E}-05$ \\
\hline standard error & $3.50 \mathrm{E}-05$ & $3.20 \mathrm{E}-05$ & \\
\hline t-stat & 1.03 & 0.52 & \\
\hline p-value & 0.3015 & 0.6034 & \\
\hline
\end{tabular}

ABSENCE OF LIMITATION IN PHYSICAL FUNCTIONING (mean $\mathbf{0} \mathbf{0 . 6 7 2}$ )

\begin{tabular}{|l|c|c|c|}
\hline vintage coefficient & $1.60 \mathrm{E}-04$ & $5.40 \mathrm{E}-05$ & $1.10 \mathrm{E}-04$ \\
\hline standard error & $4.80 \mathrm{E}-05$ & 0.000041 & \\
\hline $\mathrm{t}$-stat & 3.36 & 1.31 & \\
\hline $\mathrm{p}$-value & 0.0008 & 0.1886 & \\
\hline $\mathrm{dPrx} / \mathrm{d} \mathrm{H}$ & $\$ 3,388$ & & \\
\hline rate of tech change & $4.4 \%$ & & \\
\hline
\end{tabular}

MEAN LEVEL OF DIFFICULTY (mean $=\mathbf{0 . 8 3 7}$ )

\begin{tabular}{|l|c|c|c|}
\hline vintage coefficient & $1.39 \mathrm{E}-04$ & $6.30 \mathrm{E}-05$ & $2.19 \mathrm{E}-04$ \\
\hline standard error & $2.70 \mathrm{E}-05$ & $2.00 \mathrm{E}-05$ & \\
\hline $\mathrm{t}$-stat & 5.15 & 3.2 & \\
\hline $\mathrm{p}$-value & $<.0001$ & 0.0014 & \\
\hline $\mathrm{dPrx} / \mathrm{d} \mathrm{H}$ & $\$ 3,900$ & $\$ 8,605$ & $\$ 2,479$ \\
\hline rate of tech change & $3.1 \%$ & $1.4 \%$ & $4.8 \%$ \\
\hline
\end{tabular}


Table 5

Interaction between vintage and initial health

Estimates of marginal vintage effects, by initial health status, from models including initial health and interaction between vintage and initial health

\begin{tabular}{|c|c|c|c|}
\hline Column & 1 & 2 & 3 \\
\hline & & marginal & \\
& marginal vintage & vintage effect, & \\
& effect, initial & initial health=1 & difference \\
& health=0 $\left(\beta_{1}\right)$ & $\left(\beta_{1}+\beta_{4}\right)$ & $\left(\beta_{4}\right)$ \\
\hline
\end{tabular}

ALIVE (mean=0.992)

\begin{tabular}{|l|c|c|c|}
\hline vintage coefficient & $1.35 \mathrm{E}-04$ & $-2.00 \mathrm{E}-05$ & $-1.60 \mathrm{E}-04$ \\
\hline standard error & $1.70 \mathrm{E}-05$ & $1.90 \mathrm{E}-05$ & $2.90 \mathrm{E}-05$ \\
\hline t-stat & 8.08 & -1.06 & -5.32 \\
\hline$p$-value & $<.0001$ & 0.2895 & $<.0001$ \\
\hline
\end{tabular}

PERCEIVED HEALTH STATUS (mean $\mathbf{0} \mathbf{0 . 4 7 6}$ )

\begin{tabular}{|l|c|c|c|}
\hline \hline vintage coefficient & $1.69 \mathrm{E}-04$ & $3.20 \mathrm{E}-05$ & $-1.40 \mathrm{E}-04$ \\
\hline standard error & $4.10 \mathrm{E}-05$ & $4.60 \mathrm{E}-05$ & $7.20 \mathrm{E}-05$ \\
\hline t-stat & 4.08 & 0.7 & -1.9 \\
\hline p-value & $<.0001$ & 0.4856 & 0.0572 \\
\hline
\end{tabular}

QUALITY OF LIFE INDEX (mean= 0.576)

\begin{tabular}{|l|c|c|c|}
\hline vintage coefficient & $1.79 \mathrm{E}-04$ & $2.90 \mathrm{E}-05$ & $-1.50 \mathrm{E}-04$ \\
\hline standard error & $3.30 \mathrm{E}-05$ & $3.70 \mathrm{E}-05$ & $5.80 \mathrm{E}-05$ \\
\hline $\mathrm{t}$-stat & 5.36 & 0.77 & -2.58 \\
\hline p-value & $<.0001$ & 0.4398 & 0.0099 \\
\hline
\end{tabular}

ABSENCE OF ANY LIMITATION WORK/HOUSEWRK/SCHL (mean $=\mathbf{0 . 6 8 7}$ )

\begin{tabular}{|l|c|c|c|}
\hline vintage coefficient & $4.90 \mathrm{E}-05$ & $2.07 \mathrm{E}-04$ & $1.58 \mathrm{E}-04$ \\
\hline standard error & $6.60 \mathrm{E}-05$ & $4.80 \mathrm{E}-05$ & $7.80 \mathrm{E}-05$ \\
\hline $\mathrm{t}$-stat & 0.75 & 4.34 & 2.03 \\
\hline $\mathrm{p}$-value & 0.4556 & $<.0001$ & 0.0427 \\
\hline
\end{tabular}

ABSENCE OF SOCIAL LIMITATIONS (mean $=\mathbf{0 . 8 1 7}$ )

\begin{tabular}{|l|c|c|c|}
\hline vintage coefficient & $7.82 \mathrm{E}-04$ & $-3.00 \mathrm{E}-05$ & $-8.10 \mathrm{E}-04$ \\
\hline standard error & $8.00 \mathrm{E}-05$ & $4.30 \mathrm{E}-05$ & $8.70 \mathrm{E}-05$ \\
\hline t-stat & 9.81 & -0.64 & -9.26 \\
\hline p-value & $<.0001$ & 0.5237 & $<.0001$ \\
\hline
\end{tabular}

PERCEIVED MENTAL HEALTH STATUS (mean $=0.629$ )

\begin{tabular}{|l|c|c|c|}
\hline \hline vintage coefficient & $-5.00 \mathrm{E}-05$ & $-2.00 \mathrm{E}-05$ & $2.70 \mathrm{E}-05$ \\
\hline standard error & $5.80 \mathrm{E}-05$ & $3.90 \mathrm{E}-05$ & $8.10 \mathrm{E}-05$ \\
\hline t-stat & -0.79 & -0.48 & 0.34 \\
\hline p-value & 0.4278 & 0.6302 & 0.7375 \\
\hline
\end{tabular}


Table 5 (continued)

Interaction between vintage and initial health

Estimates of marginal vintage effects, by initial health status, from models including initial health and interaction between vintage and initial health

\begin{tabular}{|c|c|c|c|}
\hline Column & 1 & 2 & 3 \\
\hline & & marginal & \\
& marginal vintage \\
effect, initial & vintage effect, & \\
initial health=1 & \\
health=0 $\left(\beta_{1}\right)$ & $\left(\beta_{1}+\beta_{4}\right)$ & $\left(\beta_{4}\right)$ \\
\hline
\end{tabular}

ABSENCE OF COGNITIVE LIMITATIONS (mean $\mathbf{= 0 . 8 7 8 )}$
\begin{tabular}{|l|c|c|c|}
\hline vintage coefficient & $3.48 \mathrm{E}-04$ & $-3.00 \mathrm{E}-05$ & $-3.80 \mathrm{E}-04$ \\
\hline standard error & $8.10 \mathrm{E}-05$ & $3.40 \mathrm{E}-05$ & $8.60 \mathrm{E}-05$ \\
\hline t-stat & 4.28 & -0.96 & -4.43 \\
\hline p-value & $<.0001$ & 0.3364 & $<.0001$ \\
\hline
\end{tabular}

ABSENCE OF LIMITATION IN PHYSICAL FUNCTIONING (mean $\mathbf{0} \mathbf{0 . 6 7 2}$ )

\begin{tabular}{|l|c|c|c|}
\hline vintage coefficient & $1.77 \mathrm{E}-04$ & $-2.00 \mathrm{E}-05$ & $-2.00 \mathrm{E}-04$ \\
\hline standard error & $6.30 \mathrm{E}-05$ & $5.00 \mathrm{E}-05$ & $7.60 \mathrm{E}-05$ \\
\hline t-stat & 2.81 & -0.38 & -2.57 \\
\hline p-value & 0.005 & 0.7054 & 0.0101 \\
\hline
\end{tabular}

MEAN LEVEL OF DIFFICULTY (mean $=0.837$ )

\begin{tabular}{|l|c|c|c|}
\hline vintage coefficient & $4.30 \mathrm{E}-04$ & $-1.00 \mathrm{E}-05$ & $-4.40 \mathrm{E}-04$ \\
\hline standard error & $5.80 \mathrm{E}-05$ & $2.30 \mathrm{E}-05$ & $6.60 \mathrm{E}-05$ \\
\hline $\mathrm{t}$-stat & 7.38 & -0.63 & -6.7 \\
\hline $\mathrm{p}$-value & $<.0001$ & 0.5282 & $<.0001$ \\
\hline
\end{tabular}


Table 6

Broad health indicators

Estimates of drug vintage coefficients from models excluding and including controls for health utilization

\begin{tabular}{|l|c|c|c|c|c|}
\hline column & 1 & 2 & 3 & 4 & 5 \\
\hline health utilization? (type) & no & yes & (prescription) & (physician) & (hospital) \\
\hline
\end{tabular}

ALIVE (mean=0.992)

\begin{tabular}{|l|c|c|c|c|c|}
\hline vintage coefficient & $6.40 \mathrm{E}-05$ & $6.30 \mathrm{E}-05$ & $-5.50 \mathrm{E}-06$ & $-6.10 \mathrm{E}-04$ & $-2.12 \mathrm{E}-02$ \\
\hline standard error & $1.00 \mathrm{E}-05$ & $1.00 \mathrm{E}-05$ & $3.20 \mathrm{E}-04$ & $2.80 \mathrm{E}-04$ & $9.38 \mathrm{E}-04$ \\
\hline $\mathrm{t}$-stat & 6.38 & 6.27 & -0.02 & -2.17 & -22.55 \\
\hline$p$-value & $<.0001$ & $<.0001$ & 0.9863 & 0.0297 & $<.0001$ \\
\hline
\end{tabular}

PERCEIVED HEALTH STATUS (mean $\mathbf{= 0 . 4 7 6}$ )

\begin{tabular}{|l|c|c|c|c|c|}
\hline \hline vintage coefficient & $1.06 \mathrm{E}-04$ & $7.90 \mathrm{E}-05$ & $-2.87 \mathrm{E}-02$ & $-1.94 \mathrm{E}-02$ & $-3.90 \mathrm{E}-02$ \\
\hline standard error & $2.50 \mathrm{E}-05$ & $2.40 \mathrm{E}-05$ & $7.76 \mathrm{E}-04$ & $6.78 \mathrm{E}-04$ & $2.31 \mathrm{E}-03$ \\
\hline t-stat & 4.27 & 3.25 & -36.94 & -28.55 & -16.87 \\
\hline$p$ p-value & $<.0001$ & 0.0012 & $<.0001$ & $<.0001$ & $<.0001$ \\
\hline
\end{tabular}

QUALITY OF LIFE INDEX (mean= 0.576)

\begin{tabular}{|l|c|c|c|c|c|}
\hline vintage coefficient & $1.10 \mathrm{E}-04$ & $8.90 \mathrm{E}-05$ & $-2.29 \mathrm{E}-02$ & $-1.56 \mathrm{E}-02$ & $-3.81 \mathrm{E}-02$ \\
\hline standard error & $2.00 \mathrm{E}-05$ & $2.00 \mathrm{E}-05$ & $6.30 \mathrm{E}-04$ & $5.51 \mathrm{E}-04$ & $1.85 \mathrm{E}-03$ \\
\hline $\mathrm{t}-\mathrm{stat}$ & 5.49 & 4.49 & -36.28 & -28.24 & -20.61 \\
\hline p-value & $<.0001$ & $<.0001$ & $<.0001$ & $<.0001$ & $<.0001$ \\
\hline
\end{tabular}

ABSENCE OF ANY LIMITATION WORK/HOUSEWRK/SCHL (mean = 0.687)
\begin{tabular}{|l|c|c|c|c|c|}
\hline vintage coefficient & $1.56 \mathrm{E}-04$ & $1.09 \mathrm{E}-04$ & $-6.48 \mathrm{E}-02$ & $-1.18 \mathrm{E}-02$ & $-8.00 \mathrm{E}-02$ \\
\hline standard error & $4.10 \mathrm{E}-05$ & $4.00 \mathrm{E}-05$ & $1.25 \mathrm{E}-03$ & $1.10 \mathrm{E}-03$ & $3.78 \mathrm{E}-03$ \\
\hline t-stat & 3.85 & 2.74 & -51.95 & -10.7 & -21.16 \\
\hline p-value & 0.0001 & 0.0062 & $<.0001$ & $<.0001$ & $<.0001$ \\
\hline
\end{tabular}

ABSENCE OF SOCIAL LIMITATIONS (mean $\mathbf{0} \mathbf{0 . 8 1 7}$ )

\begin{tabular}{|l|c|c|c|c|c|}
\hline vintage coefficient & $1.37 \mathrm{E}-04$ & $9.80 \mathrm{E}-05$ & $-5.87 \mathrm{E}-02$ & $-4.97 \mathrm{E}-03$ & $1.47 \mathrm{E}-02$ \\
\hline standard error & $3.90 \mathrm{E}-05$ & $3.80 \mathrm{E}-05$ & $1.20 \mathrm{E}-03$ & $1.06 \mathrm{E}-03$ & $3.60 \mathrm{E}-03$ \\
\hline $\mathrm{t}-\mathrm{stat}$ & 3.53 & 2.55 & -49.14 & -4.67 & 4.09 \\
\hline$p$-value & 0.0004 & 0.0106 & $<.0001$ & $<.0001$ & $<.0001$ \\
\hline
\end{tabular}


Table 6 (continued)

Broad health indicators

Estimates of drug vintage coefficients from models excluding and including controls for health utilizatio

\begin{tabular}{|l|c|c|c|c|c|}
\hline column & 1 & 2 & 3 & 4 & 5 \\
\hline health utilization? (type) & no & yes & $(\mathrm{rx})$ & (hosp) & (phy) \\
\hline
\end{tabular}

PERCEIVED MENTAL HEALTH STATUS (mean = 0.629)

\begin{tabular}{|l|c|c|c|c|c|}
\hline vintage coefficient & $-3.00 \mathrm{E}-05$ & $-5.00 \mathrm{E}-05$ & $-2.08 \mathrm{E}-02$ & $-1.15 \mathrm{E}-02$ & $-3.19 \mathrm{E}-02$ \\
\hline standard error & $2.60 \mathrm{E}-05$ & $2.60 \mathrm{E}-05$ & $7.98 \mathrm{E}-04$ & $7.15 \mathrm{E}-04$ & $2.45 \mathrm{E}-03$ \\
\hline $\mathrm{t}$-stat & -1.10 & -1.91 & -26.04 & -16.01 & -13 \\
\hline p-value & 0.271 & 0.0561 & $<.0001$ & $<.0001$ & $<.0001$ \\
\hline
\end{tabular}

ABSENCE OF COGNITIVE LIMITATIONS (mean $\mathbf{0} \mathbf{0 . 8 7 8}$ )

\begin{tabular}{|l|c|c|c|c|c|}
\hline vintage coefficient & $1.70 \mathrm{E}-05$ & $-6.89 \mathrm{E}-06$ & $-2.13 \mathrm{E}-02$ & $-5.18 \mathrm{E}-03$ & $-9.19 \mathrm{E}-02$ \\
\hline standard error & $3.20 \mathrm{E}-05$ & $3.20 \mathrm{E}-05$ & $9.75 \mathrm{E}-04$ & $8.77 \mathrm{E}-04$ & $2.96 \mathrm{E}-03$ \\
\hline $\mathrm{t}-\mathrm{stat}$ & 0.52 & -0.22 & -21.84 & -5.91 & -31.1 \\
\hline$p$ p-value & 0.6034 & 0.8276 & $<.0001$ & $<.0001$ & $<.0001$ \\
\hline
\end{tabular}

ABSENCE OF LIMITATION IN PHYSICAL FUNCTIONING (mean $\mathbf{0} \mathbf{0 . 6 7 2}$ )

\begin{tabular}{|l|c|c|c|c|c|}
\hline vintage coefficient & $5.40 \mathrm{E}-05$ & $1.30 \mathrm{E}-05$ & $-5.09 \mathrm{E}-02$ & $-2.27 \mathrm{E}-02$ & $-7.16 \mathrm{E}-02$ \\
\hline standard error & $4.10 \mathrm{E}-05$ & $4.00 \mathrm{E}-05$ & $1.27 \mathrm{E}-03$ & $1.12 \mathrm{E}-03$ & $3.84 \mathrm{E}-03$ \\
\hline $\mathrm{t}$-stat & 1.31 & 0.33 & -40.23 & -20.24 & -18.66 \\
\hline p-value & 0.1886 & 0.7405 & $<.0001$ & $<.0001$ & $<.0001$ \\
\hline
\end{tabular}

MEAN LEVEL OF DIFFICULTY (mean $=\mathbf{0 . 8 3 7}$ )

\begin{tabular}{|l|c|c|c|c|c|}
\hline vintage coefficient & $6.30 \mathrm{E}-05$ & $4.80 \mathrm{E}-05$ & $-1.77 \mathrm{E}-02$ & $-3.47 \mathrm{E}-03$ & $-5.32 \mathrm{E}-02$ \\
\hline standard error & $2.00 \mathrm{E}-05$ & $2.00 \mathrm{E}-05$ & $6.14 \mathrm{E}-04$ & $5.40 \mathrm{E}-04$ & $1.86 \mathrm{E}-03$ \\
\hline t-stat & 3.20 & 2.48 & -28.77 & -6.42 & -28.67 \\
\hline$p$ p-value & 0.0014 & 0.0132 & $<.0001$ & $<.0001$ & $<.0001$ \\
\hline
\end{tabular}

